\title{
Adaptation finance archetypes: local governments' persistent challenges of funding adaptation to climate change and ways to overcome them
}

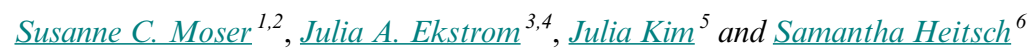

\begin{abstract}
Faced with increasing climate extremes and climate change impacts, local governments in California are eager to advance their adaptation measures and build local resilience. However, as previous studies and day-to-day interactions with local leaders make clear, identifying ways to resource adaptation is one of the most significant barriers to progress. This paper draws on selected findings from a study that aimed to better describe the nature of the adaptation finance challenges local governments face so as to find ways to overcome them. Building on initial findings from an online survey and nine stakeholder workshops to deepen the understanding of the nature of funding and financing challenges for local governments, we use a methodological innovation in archetype analysis, grounded theory, to develop a suite of 15 archetypal adaptation finance challenges, i.e., repeatedly found patterns of interrelated causal factors, traits, and outcomes ranging from establishing a matter of concern worthy of attention (and funding) to acquiring, using, and managing adaptation finance. These archetypes are found across different types and sizes of local governments facing different climate change threats. The resulting deeper understanding of local adaptation funding challenges represents an important contribution to the literature and opens up new avenues for intervention beyond the prevailing focus on creating new funding vehicles. We offer archetypespecific recommendations to overcome or reduce these critical finance challenges in local climate change adaptation.
\end{abstract}

Key Words: archetype analysis; barriers; California; climate change adaptation; finance; local government

\section{INTRODUCTION}

U.S. national and international studies have identified funding for climate change adaptation planning and implementation as a persistent challenge impeding greater progress in preparedness to the impacts of accelerating climate change (Carmin et al. 2012, Aylett 2014, Bierbaum et al. 2014, Klein et al. 2014). Internationally, the problem is discussed at the highest levels, in particular to identify ways and means to support adaptation in the least developed countries (UNFCCC 2008, AGF 2010, Trabacchi and Mazza 2015), and there is now also a growing focus on identifying adaptation resources within the U.S. Lack of adaptation funding, however, is seriously hampering adaptation efforts across the U.S., and concerns have increased since the arrival of the Trump Administration (Moser et al. 2017).

In the hopes to generate new sources of funding, there has been a nearly exclusive focus on finance mechanisms with little focus first on establishing the precise nature of local finance challenges. One of this study's main contributions is to attempt to fill this gap by using archetype analysis to better characterize the nature of the finance challenges and thus to contribute to finding feasible and effective solutions. Archetype analysis aims to identify patterns of repetitive associations of attributes, and relationships among them, that hold across numerous cases or observations. Midlevel between the particularities of individual cases and highlevel theory building, archetype analysis abstracts to common associations among factors to conceptually explain why certain repeatedly observed phenomena occur (Oberlack and Eisenack 2018, Eisenack et al. 2019, Oberlack et al. 2019).

We focus on California, where interest in climate adaptation has notably advanced over the last decade, yet where funding barriers have been found to be substantial (Finzi Hart et al. 2012, Moser and Ekstrom 2012, Bedsworth and Hanak 2013, Ekstrom et al. 2017, Moser et al. 2018a). Focusing on California as a lens through which to better understand U.S. and developed countries' adaptation finance challenges is significant in that the state, and many local governments within it, are or are perceived to be wealthy, and yet previous research established that finding the necessary means for adaptation has been a challenge even for wealthy communities (Moser and Ekstrom 2012). Insights gained here may thus be relevant to and testable across the nation and in other countries.

\section{LITERATURE REVIEW}

Adaptation barriers: the persistent importance of lack of funding Despite the emergence of climate change impacts and climaterelated disasters, making the necessity increasingly apparent to prepare for and deal with these impacts and disruptions, implementation of adaptation actions has been hampered across the world and in the U.S. (Bierbaum et al. 2014, Klein et al. 2014, Moser et al. 2017, Sovacool et al. 2017). There is strong consensus on the main, overarching barrier themes and there are many other, more nuanced barriers within and exacerbating these broader challenges. Researchers also agree that barriers are highly contextspecific (Moser and Ekstrom 2010, Measham et al. 2011). Six categories of barriers emerge repeatedly in the literature in the U. S. and, specifically, in California:

$$
\begin{aligned}
& \text { - financial/resources; } \\
& \text { - institutional/governance/legal; } \\
& \text { - staffing capacity; } \\
& \text { - informational/uncertainty; } \\
& \text { - attitudinal; and } \\
& \text { - political. }
\end{aligned}
$$

Of these, financial and resource constraints are indeed the most frequently discussed, with nearly three-quarters of articles reviewed in our systematic literature review (for full review, see

${ }^{1}$ Susanne Moser Research \& Consulting, ${ }^{2}$ Antioch University New England, ${ }^{3}$ Climate Change Program, California Department of Water Resources, ${ }^{4}$ Policy Institute for Energy, Environment and the Economy, University of California, Davis, ${ }^{5}$ Local Government Commission, ${ }^{6}$ ICF International 
Moser et al. 2018a). However, this class of funding-related barriers has not been explored in any detail at any level of governance. As in much of the barriers literature, studies catalogue but do not explain adaptation finance challenges (e.g., Eisenack et al. 2014, Biesbroek et al. 2015). And although Moser and Ekstrom (2010) in their diagnostic framework of adaptation barriers introduced the concept of "legacy barriers" to point to the historical roots of many barriers, deeper analysis is yet required to adequately resolve financial barriers.

Some barrier studies explicitly rank the importance of different barriers, and often (but not always) find funding to be the leading barrier. For example, Moser et al. (2018b) and Finzi Hart et al. (2012) found in a longitudinal survey of coastal managers in California that three of the four biggest hurdles to adaptation relate to insufficient resources and lack of funding. Moser and Ekstrom (2012) found that the third-most important category of barriers to adaptation in local and regional governments in the San Francisco Bay Area was also related to resources and funding.

\section{Key concerns regarding adaptation finance}

Despite the prevalence of insufficient resources, most of the literature on both available and proposed funding and financing mechanisms for climate change adaptation focuses on international development and disaster assistance, particularly the transfer of monies from Annex-1 countries toward developing nations. Of the articles we reviewed that pertained directly to adaptation funding and financing mechanisms, 36 out of 48 articles focused on development and the link between development aid and adaptation finance (Moser et al. 2018a). Generally, experts agree that available adaptation funding is not commensurate with adaptation needs (Smith et al. 2011, Barnard 2015, UN Global Compact et al. 2015, Bendandi and Pauw 2016, Coffee 2016, Nhamo and Nhamo 2016, Robinson and Dornan 2017).

Importantly, the funding streams emanating from the UNFCCC are not accessible to communities in developed nations. Europe has set up funding mechanisms for countries within the EU (European Commission 2013). There is nothing at that scale available at present in the U.S., although prior to the Trump Administration, federal leadership enabled various federal agency programs to explicitly support state and local adaptation efforts, and previous research found this federal financial support, together with philanthropic investment, to be a key driver behind advances in the U.S. adaptation field in recent years (Moser et al. 2017).

Across this body of literature, there is a growing concern with social equity and justice in adaptation finance. Generally, research has found that the infusion of international climate adaptation finance into national and subnational contexts can lead to or perpetuate injustice (Barrett 2013). In addition, those most vulnerable often do not have the capacity to receive or utilize the financing they desperately need (Webber 2013, Barrett 2014). This concern is only beginning to emerge in the U.S. domestic literature on adaptation finance (and in practice).

\section{The narrow search for solutions}

As a result of the pervasive lack of resources for adaptation, identifying adaptation finance mechanisms to generate new sources of funding has become a growing, and dominant, concern in the U.S. Efforts are underway to develop creative and novel finance mechanisms (e.g., Barnard 2015, Build America Investment Initiative 2015, re:focus partners 2015, 2017, Zimring et al. 2015, NHA Advisors 2017; Snyder and Valdez 2015 blog, https://www.pillsburylaw.com/en/news-and-insights/enhancedinfrastructure-districts-a-flexible-new-tool-for-local.html).

Many have proposed that the private sector take on a far more significant role in resourcing adaptation. However, it is apparent that under current conditions, there is little incentive for private entities to invest their funds, largely because adaptation measures on their own do not necessarily yield a return on investment; there is an insufficiently developed project pipeline ready for investment and the governance structures are lacking to receive and manage complex financial interactions (OECD and Bloomberg Philanthropies 2014, Pauw 2017). In addition, there is little detailed familiarity between private and public-sector actors (Moser et al. 2017), and the support structure to navigate between the government and investment worlds is only beginning to emerge. $^{[1]}$

With such challenges in mind, experts often cite a need for a legal mandate or other top-down institutional support for adaptation in order to spur funding (Moser 2007, Measham et al. 2011, Finzi Hart et al. 2012). In California, state legislation now mandates inclusion of climate change considerations in the safety element of general plans (albeit without additional funding) ${ }^{[2]}$ California also has established the Integrated Climate Adaptation and Resiliency Program (ICARP, established through SB 246), to improve coordination around and point to (but not itself provide) funding for adaptation. ${ }^{[3]}$

Adaptation finance mechanisms, in various stages of development at present, are the dominant focus of discussion (see Moser et al. 2018a). At the time of our study, however, no indepth analysis existed as to whether these mechanisms, e.g., green or climate bonds, resilience bonds, various insurance mechanisms, would meet the needs and match the capacities of local governments. Moreover, there are no case studies available to provide at least place-based, in-depth analysis, nor are there broader, systematic studies to date providing much insight. Against a backdrop of calls for more emphasis on explaining, rather than just describing and cataloguing, adaptation barriers (e.g., Eisenack et al. 2014, Biesbroek et al. 2015, 2017), the present study aims to begin to fill this void.

\section{Deepening the understanding of adaptation finance challenges: archetype analysis}

In this study, we build on a long-standing type of analysis in the global change literature, called archetype analysis, to better describe and examine repeated patterns of commonly found sets of factors or attributes (Oberlack and Eisenack 2018, Eisenack et al. 2019, Oberlack et al. 2019). Informed by systems thinking, complexity theory, and, in particular, the articulation of system archetypes (Kim 1992) along with explorations of leverage points to intervene in complex systems (Meadows 1999), archetype analysis also draws on the extensive work in the lineage of Elinor Ostrom, examining the institutional arrangements supporting effective (and less effective) natural resource management, particularly common pool resources (e.g., Ostrom 1990, Keohane and Ostrom 1995). Archetype analysis aims to understand the systemic nature of observed problems and their characteristic 
trajectories of change, without losing sight of the contextspecificity of challenges that prevent easy generalizations and policy prescriptions.

Enabled by the growing availability of powerful computational and modeling tools, archetype analysis grew out of the need for an understanding of persistent challenges at an intermediate level of complexity and generalizability. The result has been a growing portfolio of studies (of which this Special Feature of Ecology and Society is now a part) that analyze various phenomena:

- Global change "syndromes" (Schellnhuber et al. 1997, Petschel-Held et al. 1999, Lüdeke et al. 2004, Srinivasan et al. 2012);

- "Archetypes" of social-ecological systems and related resource management challenges, including the analysis of underlying institutional arrangements such as polycentric governance systems and "(networked) action situations" (McGinnis 2011, Kimmich 2013, Cumming 2016, Kimmich and Tomas 2019; Eisenack, Lüdeke, and Kropp 2006, unpublished manuscript: https://www.uni-oldenburg.de/ fileadmin/user_upload/wire/fachgebiete/envdev/download/archeisenack3.pdf);

- System archetypes of social-technological-economic systems, e.g., energy systems (Kasperson et al. 1995, Dangerman and Schellnhuber 2013);

- Land systems, their trajectories of change, and long-distance influences on land systems via telecoupling (Václavík et al. 2013, Eakin et al. 2014, Messerli et al. 2014, Levers et al. 2018);

- (Nested) vulnerabilities to climate and other environmental changes (Blaikie 1985, UNEP 2007, Sietz et al. 2011, 2017, Kok et al. 2016, Oberlack et al. 2016);

- Climate change adaptation barriers (Eisenack 2012, Oberlack and Eisenack 2014, Oberlack 2017; Eisenack, Lüdeke, and Kropp 2006, unpublished manuscript); and

- Assessment of the robustness of policy and management intervention in conservation (Cundill et al. 2012) and climate change adaptation contexts (Proust et al. 2012, Jäger et al. 2015).

Studies such as these typically (but not exclusively) employ theorydriven, deductive, often quantitative meta-analyses of existing case material to identify and examine archetypes. Others have used geospatial, fuzzy logic, integrated modeling, or artificial neural networks. Although their nominal focus, i.e., the systems or patterns of interest vary, they share a common, basic understanding of archetypes as recurrent patterns of functional relationships between a set of drivers, factors, or attributes. Building on the syndromes concept, Eisenack (2012:110) defined archetypes as "representative patterns of the interaction between society and nature bringing about global environmental change and/or being responses to such changes." Furthermore, they are "building blocks of social-ecological interactions that reappear in multiple case studies" (Eisenack 2012:110) and as such are not necessarily found in each case. Rather, individual cases are often constituted of several archetypes, while different cases can display different combinations of archetypes. As consistent building blocks, they point to similarities in the underlying factors and thus offer leverage points for policy intervention (Oberlack and Eisenack 2014).

Existing studies of archetypes in the climate vulnerability and adaptation context have focused on typical patterns of socialecological vulnerability or on recurrent sets of adaptation barriers to understand adaptation outcomes. In these studies, the capacity to pay for adaptation interventions emerged consistently as a critical factor but is typically listed as one of many factors impeding adaptation progress. The patterns of factors creating this inability to finance adaptation actions themselves, however, have not or only rudimentarily been examined. A focus on institutional barriers has dominated most of these studies to date given their importance (Moser 2009), while economic, political, psycho-social, cultural, geographic, or scientific factors have been viewed as separate from each other, secondary, or contributory to institutional barriers. In the present study, we examine these factors as interactive drivers or explanatory variables of adaptation finance challenges.

\section{METHODS}

The empirical portion of the research involved an online survey and nine stakeholder workshops. The survey helped develop an overview of the state of adaptation and initial insights into finance challenges, which served as an input into the stakeholder workshops. The workshops provided the qualitative data from which the archetypes were derived.

\section{Survey}

We conducted a survey consisting of 19 questions; most of them involved simple nominal or rating questions. Questions focused on demographics, climate change adaptation generally, and on funding and financing adaptation.

The survey was open to local government officials and those closely working with them for 13 months from 28 June 2016 and 27 July 2017. We collected 233 viable responses for analysis. Further information on the sample, its geographic and sectoral representation, and survey questions are provided in Appendix 1. Survey data were analyzed using statistical software and resulting in simple descriptive statistics.

\section{Workshops}

The data underlying the archetype analysis come from nine workshops conducted between August 2016 and January 2017 across California (San Diego, Los Angeles, Central Coast, San Francisco Bay Area, Capitol Region, Central Valley, North Coast, Sierra Nevada, and an open workshop [without regional specificity] at the 2016 Third California Adaptation Forum in Long Beach), with the following specific objectives: hearing directly from local government staff and from organizations supporting local government efforts on the financing and institutional barriers they face; and discussing and exploring potential strategies to overcome these barriers.

Attendants included local government officials and others supporting local governments with adaptation (consultants, NGOs, etc.). Participation was uneven across the nine workshops, reflecting the number of individuals in each region interested and already engaged in adaptation. A total of 149 people participated across the nine workshops. Workshops were typically half-day in 
length, held in centrally located public facilities, facilitated by the authors and additional collaborators using a consistent facilitation agenda, and structured so that half of the time was allocated to the question of adaptation finance challenges. ${ }^{[4]}$ Trained volunteers took notes during whole-group and break-out group discussions. These detailed, sometimes nearly verbatim notes, formed the basis for analysis (described below). The structure of the workshops and the prompts given to participants to elicit views on these challenges are detailed in Appendix 1.

\section{Grounded theory}

Our goal was to identify common patterns of finance challenges and the causal drivers underlying them in workshop participants' eyes, not to conduct an objective systems analysis or a theoretically driven analysis. (This could be viewed as a strength or weakness, and future analyses could assess and validate, or not, those found to strengthen confidence in our findings.) Thus, after the conclusion of all workshops, detailed workshop notes collected by trained volunteers were inductively labeled (often using key phrases repeatedly used by participants) and sorted, using grounded theory (Glaser and Strauss 2011, Walsh et al. 2015). Grounded theory, though while well established in the social sciences, constitutes a methodological innovation in archetype analysis. It begins from stakeholder's own perceptions of a given matter of concern and tries to understand how they explain those matters. Although not focused on establishing consensus views, grounded theory identifies (groupings of) issues mentioned repeatedly, and then uses those repeatedly found issues to anchor subsequent rounds of analysis that focus on understanding underlying explanations and repercussions of the noted challenges. The analyst's role is to look for patterns among the problems identified across all workshops (in this case, across regions, types of climate risks, types and sizes of local government entities etc.), as well as among the explanatory factors underlying them and for associated consequences of those constellations. This is a qualitative procedure of discovery, grouping, and association, rather than a formal, quantitative procedure.

Iterative and recursive processing of workshop notes in this fashion helped commonly found adaptation finance challenges to rise to the fore. The deliberative search for patterns revealed characteristic associations among the following:

- observed finance challenges (often, the first-order complaint or problem experienced);

- core anchors or focal points of each challenge (an organizing principle that associated the observed challenge with a stage in the process of obtaining/using adaptation finance);

- a set of underlying contributory factors or attributes (stakeholders' own explanations for why these problems existed); and

- characteristic (and defining) outcomes on local governments' ability to proceed with acquiring/using adaptation funds.

Each archetype is thus constituted of these four dimensions: an observed phenomenon occurring (or anchored) at a key stage in the funding process, caused by a characteristic set of underlying and interacting drivers, resulting in defining outcomes. In this way, the analysis revealed a suite of 15 unique archetypes, several with notable subtypes/variants or specific expressions in different contexts.

\section{RESULTS}

\section{Initial insights: selected survey findings}

To set the context for the archetypes identified, we first report on selected findings from the survey (more fully reported in Appendix 2 and Moser et al. 2018a). Because finance challenges may inhibit entering, and differ over the course of, the adaptation process, the survey helped establish how far along respondents reported to be in their adaptation process. Ninety percent of survey respondents reported to have at least begun the adaptation process. Applying the adaptation process stages used in Moser and Ekstrom (2010), $45 \%$ of survey respondents reported to be in the initial understanding stage. Nearly $80 \%$ of respondents reported funding as a major hurdle to their adaptation processes, reflecting that even in early stages of adaptation processes, funding and financing can be critical.

The survey helped to generate an initial, albeit superficial characterization of adaptation finance challenges. Respondents reported insufficient staff time most frequently (60\%), while nearly as many noted that they had some funding, but that it is insufficient to meet their needs. These were followed by not knowing where to go for adaptation funding or how to assess adaptation costs (Fig. 1). Approximately one-third of respondents reported not meeting requirements of available funds and the same proportion expressed that they do not have the required matching funds.

When asked how respondents had overcome these finance-related challenges, only 79 survey participants responded to this question, indirectly confirming the importance of this type of barrier that many had not overcome yet. Mainstreaming was the most common approach reported to overcome funding barriers, followed by creating a budget-line item for adaptation-related activities. Neither of these strategies offers new funds to cover the additional costs that adaptation may require.

\section{Constructing the landscape of adaptation finance archetypes}

The archetype analysis aimed to create a deeper understanding of the finance challenges and the limited solutions sought to date. It distinguished three core dimensions or building blocks: (1) the economic, political, institutional, human capital, cultural and psycho-social, scientific-informational, and geographic or physical factors contributing to the archetypal patters (attributes); (2) the focal point of the archetype that anchored the challenge and its associated attributes; and (3) the immediate outcome of the archetypal challenge on the ability of local governments to obtain adaptation funds.

The analysis revealed seven focal points around which the adaptation finance challenges clustered, following a logicaltemporal sequence from issue identification to acquiring and using funding:

- Establishing climate change risks and adaptation as a matter of concern (a prerequisite to bringing attention to and prioritizing an issue for funding);

- Establishing the funding need, which involves assessing and justifying adaptation expenditures; 
Fig. 1. Barriers specifically related to acquiring adaptation funding.

Barriers Related to Acquiring Adaptation Funds

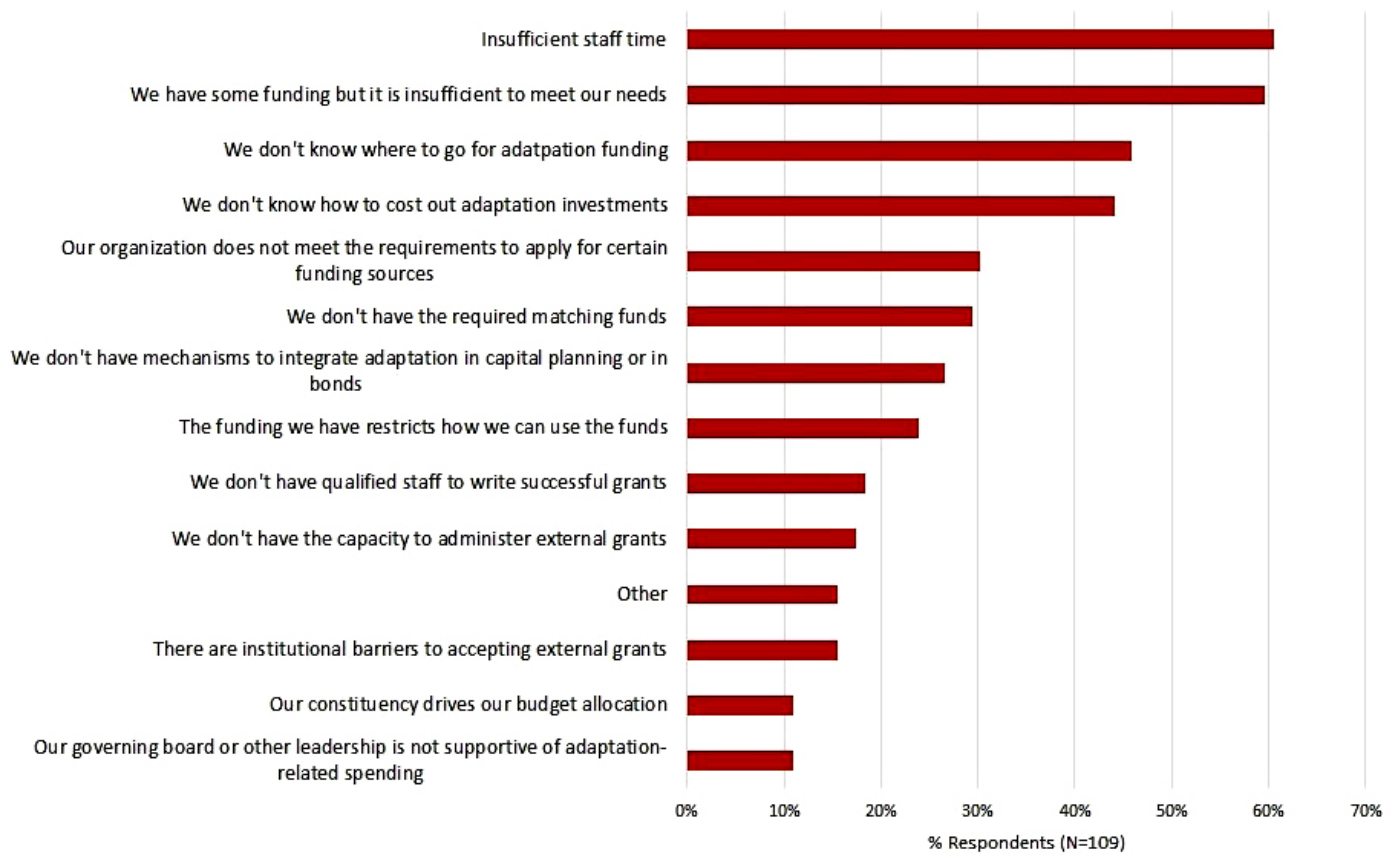

- Proving the financial standing (capacity) of the funding seeker;

- Identifying and accessing funding providers;

- Accessing different types of funding or financing;

- Navigating specific funding mechanisms; and

- Having or creating the ability to use and administer funds.

Figure 2 places the contributing factors, anchors, and immediate outcomes in relationships to each other in a simple matrix. Together, they frame the landscape of archetypes uncovered. The archetypes are named with a brief descriptor, either using workshop participants' own words or a synthetic term assigned by the researchers.

Figure 2 emphasizes the major contributory factors underlying each archetype, but often multiple factors contribute. For simplicity's sake, only the dominant contributory factor or factors are shown. In reality, any number of underlying factors varying in significance can contribute to an archetype. In fact, it is this interlocking of underlying drivers and barriers that creates the stability of these characteristic patterns and suggests why they are so difficult to change.

\section{Archetypes: problems and possible solutions}

The description and discussion of archetypes, including their characteristic manifestation and underlying causes are listed in sets, according to the core issue or anchor to which they pertain. More detailed description of each archetype along with possible solutions is presented in tabular form for each archetype in Appendix 2.
Focal point 1: Establishing climate change risks and adaptation as a matter of concern

The first set of archetypes relate to the challenge of getting climate change risks and the need for adaptation onto the local political agenda. Without being able to attain some level of importance or priority, local governments will not bother to allocate staff or funding resources toward it. Importantly, such perceptions of importance or urgency may not be universally shared across staff and superiors/elected officials.

Four archetypes fall into this category: Low Priority, Lack of Champion/Leadership, Conflict of Interest, and Disproportionate Burden/Prior Disadvantage. We discuss them sequentially, but many participants viewed them as deeply interrelated. Together, the outcome is that a local government entity may not be able to get started with assessing adaptation needs and obtaining necessary funds.

The Low Priority archetype is present when adaptation and planning for the long-term future is perpetually placed on the "back burner" behind more immediate or salient issues. The most common cause mentioned was the "tragedy of urgency" (or of immediacy), i.e., the constant pressure from immediate needs or daily demands. Other underlying causes include the lack of understanding of climate change and the risks it poses, and sometimes the lack of desire to want to know. At this stage, it is not unusual to not have a line-item for it in the local budget, which would create its own pressure for attention. Possible interventions on this archetype include education and trainings for local government staff and elected officials; help with framing, communication, and engagement, particularly of skeptical audiences; and top-level mandates that adaptation planning be undertaken. 
Fig. 2. The landscape of adaptation finance archetypes circumscribed by underlying contributing factors, focal points, and immediate funding-related outcomes.

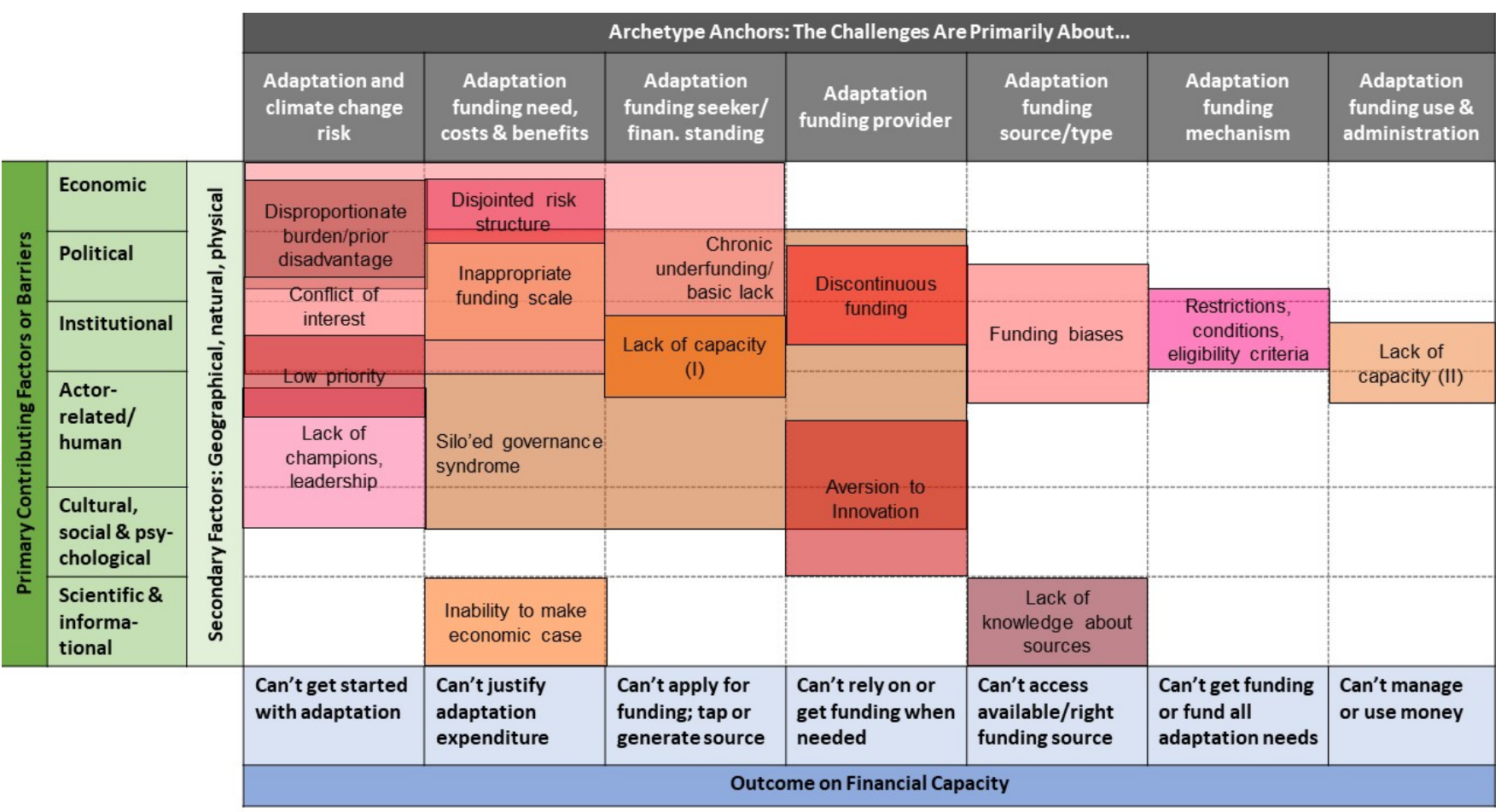

The Lack of Leadership archetype is distinct if related. One of the primary causes mentioned repeatedly by participants was a sense of weak government and lack of empowerment among individuals within local government. Although many emphasized that leadership can come from any position in the hierarchy, toplevel leadership from a supervisor, mayor or other elected official is commonly critical to get adaptation on the agenda. Participants made clear: when there is leadership, funding follows. Nearly everyone spoke of the "politics" of taking on climate change, particularly in rural and conservative areas, but political calculus plays a role even in more progressive contexts. Possible interventions mentioned include local and state mandates to provide cover for local politicians and neighboring community leaders serving as "ambassadors" to those not yet taking action.

The Conflict of Interest archetype does not only emerge out of a current set of conditions and interests but points to deep-seated, institutionalized, and often physically manifest interests with long historical roots. At the core of this archetype is the fact that although local government has an interest in protecting itself from the risks of climate change, it simultaneously has an interest in ignoring it because of the expenditures or lost revenues it may involve. It forces local officials to deal with challenging trade-offs, e.g., protecting a shoreline with a seawall may result in the loss of the beach that is the foundation of the local beach tourism economy. Local officials may choose to neglect the fiscally and politically less expensive issue (adaptation) in favor of interests that have a stronger constituency or promise greater near-term benefits. Strong and persistent leadership, backed by a populace demanding change, as well as education and training in how to link adaptation to local agencies' core missions are required to overcome this deep-seated archetype.

The fourth archetype in this first class, Disproportionate Burden, spans across this and the next two focal points (of establishing adaptation funding needs and the fiscal standing of the funding seeker), but we discuss it here because it can prevent adaptation from rising to the top as a matter of concern. This archetype has a number of subtypes or variations, demanding different policy instruments, including disproportionate burdens experienced by (a) small communities; (b) minority and/or low-income communities; (c) small businesses; (d) rural, remote, thinly populated, and/or unincorporated areas; (e) areas with an already-high tax burden; (f) areas with a particularly high climaterisk burden; and (g) future generations. The causes root in institutionalized racism, long neglect of remote and low-income communities, legacies of deferred infrastructure maintenance and persistent lack of investment in education, diverse local economies, health care, environmental protection, and so on. Together, they result in current issues being more pressing, longstanding vulnerabilities, and low adaptive capacity of local governments. Possible interventions must address these causes systemically and in a sustained manner through broad policy interventions, but even smaller targeted approaches can be useful, such as through providing more capacity grants, grant writing services to the disadvantaged, or charging fees for nonparticipation in adaptation planning. 


\section{Focal point 2: Establishing adaptation funding need, costs, and} benefits

The second class of archetypes relate to the challenge of establishing the funding need, i.e., to the ability to assess and justify costs and benefits of adaptation. It includes a set of three interlinked challenges that may prevent communities from persuasively arguing for funding.

The first archetype here, Inappropriate Funding Scale, is driven largely by institutional factors and the geographic nature, scale, and scope of the climate change problem, which can feed into psycho-social barriers. For example, climate change as a global problem is so big, affects multiple systems at once, does not respect jurisdictional boundaries, and many solutions, to be effective, must transcend institutional structures and boundaries. This creates a fundamental mismatch between the problem and effective solutions on the one hand and the capability, authority, and set up of local governments on the other. Related to that is a question of responsibility and liability for climate change impacts. In the absence of having a clear agreement to address adaptation funding locally, it is difficult to convince those already hesitant or burdened with other costly challenges to add adaptation to their list of funding priorities. Possible interventions include funded mandates, block grants, or assuming that there will not be any state/federal funding assistance, thus spurring radical rethinking of solutions.

The second archetype in this class is Disjointed Risk Structure, which describes the situation where those enjoying the benefits of residing in or using highly desirable locations and resources that are also at risk from climate impacts do not carry a commensurate share of the burden of keeping them safe. For example, developers may profit from the sale of a prime-location (but at-risk) property, but owners or occupants will face the financial burden of addressing climate impacts. Long-standing interest politics and associated institutionalization of risk structures have maintained a situation where the true risk and cost is not borne by those enjoying the greatest benefit. Policy interventions to deincentives living in risky places and foster development of funds to address these risks through adaptation; incentives to mitigate hazards on an ongoing basis; and creating "benefit districts" to generate adaptation funding from the most capable property owners were among the possible solutions offered.

The third archetype, Inability to Make the Economic Case, is a frequently mentioned challenge with three subtypes: (a) the inability to assess the cost of inaction, i.e., demonstrate the need; (b) the challenge of valuing uncertain risks and benefits; and (c) the ability to adequately compare monetary and nonmonetary values. As a result, local governments cannot justify the expense for adaptation vis-à-vis other potential budget items. This archetype is strongly scientific and technical in nature. Consequently, potential solutions offered included more research on adaptation costs and benefits; advances in establishing common sets of metrics of success and performance; and staff trainings in the most useful economic tools.

\section{Focal point 3: Proving the fiscal standing of the adaptation funding seeker}

Three distinct archetypes constitute the third class of challenges related to adaptation finance, which are about the adaptationfunding seeker and profoundly affect their ability to apply for funding/financing or tap/generate a steady source of funding. First, the Chronic Underfunding archetype speaks to a fundamental condition that most local U.S. governments face, namely a culture of limited government and widespread tax aversion. More specifically, California is a tax-restricted state, ${ }^{[5]}$ meaning local governments are limited in their ability to raise taxes and in how taxpayer money is used. Existing tax law has significant implications for political maneuvering and outreach should a local government wish to increase its revenue base through a local tax: the hurdle is difficult, though not impossible to overcome. It is easier to locally raise special fees but such fees are more restricted. Consequently, local governments are highly dependent on grant funding, which creates the need to spend considerable time writing grants without assured outcome. Workshop participants noted how this favors the larger, highcapacity cities and counties, while systematically perpetuating the disadvantage of smaller, lower capacity governments. Moreover, the public feels overtaxed already, but expect local governments to provide adequate services and guard its safety. Participants overwhelmingly noted that adaptation cannot be addressed through grants alone. The solutions to this archetype would require profound rethinking of California local government funding and taxation policy, but also reframing adaptation as redevelopment, and making creative use of carrot and stick approaches to get adaptation done.

One of the most frequently cited challenges was the Siloed Government Syndrome. This well-known problem of disconnects emerged in six variations: (a) within one jurisdiction; (b) across jurisdictions and types of government, e.g., tribal vs. local government; (c) across sectors; (d) across levels of government; (e) across private and public sectors; and (f) across the rural-urban divide. The structure of government is fundamentally at odds with a problem that does not respect sectoral, geographic, or jurisdictional boundaries. This results in unclear responsibilities, leadership, accountability, and authority within and among jurisdictions. To the extent higher capacity units take the leads, lower capacity entities may or may not have equal say; fair cost and benefit distribution, work burden, and timely distribution of funds throughout a coordinated process are also challenging. As a result, budgeting is just as siloed as the rest of government functions. Possible interventions included informal learning and collaborative networks; leadership demanding cross-sector/ agency accounting of costs and benefits of projects within the local budget framework; funding for coordinating entities; and shifts in narratives to "shared opportunities."

The final archetype in this category, Lack of Capacity, affects the ability to apply for funding or tap/generate a funding source. Where local governments are already "in the red," staff cuts or greater work burden on existing staff can be a challenge. Some never recovered to full staff capacity after the Great Recession in 2007/2008. Limited staff capacity causes many existing obligations to be done with delays, to remain undone all together, or leave little to no capacity to think about how adaptation could be woven into existing work and funding streams. Given the tax law-driven dependence on external grant funding, lack of staff limits the capacity to look for grant opportunities, the ability to make sense of foundation and government grant funding, which is dispersed and difficult to navigate. Moreover, limited staff capacity constrains the ability to apply for grants that could 
increase capacity. Although bigger cities and counties may have a "dedicated adaptation person," many do not have that luxury. Most government employees must add adaptation to the "many hats they already wear." Staff turn-over, low confidence in the ability to be successful, and high competition for particular grant opportunities can result in local government staff not even trying to apply for funding. Reducing onerous grant-writing requirements; scaling up internship programs particularly in lowcapacity communities; and providing more capacity or block grants were among the many suggested interventions.

\section{Focal point 4: Identifying and accessing adaptation funding provider}

The fourth set of archetypes rest, in the eyes of workshop participants, with the funding providers. As a class, the challenges described here significantly contribute to the fact that local governments cannot rely on or find appropriate funding opportunities when and where they need them. There are two archetypes in this category.

The Discontinuous Funding archetype is fundamentally about the disconnect between the dynamic and ongoing nature of climate change and hence that of adaptation and a tradition of short-term, finite funding for projects and even programs. We found two variations on this archetype: (a) funding of continual change; and (b) funding pre- and postdisaster. In the words of workshop participants: "climate change is ongoing, but funding comes and goes." They bemoaned how difficult it is in general to get longer term funding ("there is no 20 -year money out there") to take a project from beginning to end. And while disasters can free up significant money, it comes all at once and goes away shortly after an event. Moreover, how that money can be used depends on the rules and regulations of recovery funds. Predisaster hazard mitigation grants were perceived as too small to cover the actual full cost of projects, so "everyone is ... doing piecemeal work," "spinning wheels without getting anywhere." Participants spoke of the need to set up "life-long funding sources" that could cover all aspects of adaptation-related work. Other suggested interventions included block grants; establishing a "climate resilience authority" that pools risk insurance premiums for larger projects; and state assistance in establishing relationships to private sector funders.

The second archetype here, Aversion of Innovation, captures the challenge that adaptation is (and will increasingly be) a deviation from traditional approaches and designs, but many funders view investment in such innovative efforts as too risky. As a result, funders can hold back adaptation and stymie experimentation. Workshop participants attributed these problems to myopic and nonstrategic thinking, lack of a long-term perspective, comfort in the status quo, lack of understanding that novel and continually updated approaches are now required, and limits on adaptation due to institutionalization of what are permissible uses of funding. Suggested interventions included strong state-level leadership to direct agencies appropriately; pilot programs to demonstrate effectiveness; and concerted efforts in establishing best or better approaches in light of continual environmental change.

Focal point 5: Accessing different types of funding or financing The fifth set of archetypes relates to particular funding types and sources. Here, local governments encounter biases toward and against certain adaptation needs, and because of the dispersed nature of adaptation funding across many sources, they often do not know what sources are available. As a result, local governments cannot access available or find appropriate funding sources.

The Funding Biases archetype is about the perception, and often reality, that there is no or only limited funding to meet adaptationrelated needs. Interestingly, we observed a bifurcation in views on these biases. Many insisted that there is more funding available for "shovel-ready" projects, i.e., the implementation stage, and less funding for predevelopment, planning, communication and engagement, monitoring and evaluation. The second, contrasting and dominant, view was that there is more money for planning, but hardly any for implementation. Generally, however, workshop participants agreed that there is a bias toward discrete, smaller projects and efforts with a corresponding bias against broader programmatic funding. Identifying adequate measures of success for longer term, complex programmatic efforts may be harder than doing so for smaller projects, another reason why they are harder to sell to potential funders. Possible interventions include establishing life-cycle funding requirements that include funding for the "soft" aspects of adaptation; or investments in research to help illustrate cost-effectiveness and success of different adaptation measures.

The second archetype, Lack of Knowledge About Funding Sources or Happenstance, captures the essence and sentiment expressed by many: the "pure luck" of hearing about a particular grant opportunity. Others felt "some are in the know, while the rest of us aren't." In a state where local governments are strongly dependent on external funding, not having a single place to go to look for grant opportunities was perceived as a big problem. Participants viewed the world of funders to be just as siloed as the world of funding seekers. As one put it, "when the funding is siloed, your work is siloed." Many bemoaned the difficulty of finding grants, of navigating and understanding sites, and "no one in charge of looking for grants" either on their staff or doing so for a region or for all local governments. Possible remedies for this challenge mentioned include establishing an easily navigable and regularly updated clearinghouse of funding opportunities; a summit of California-focused foundations to help them see why they should include adaptation in their missions/portfolios; and creation of a statewide adaptation fund.

\section{Focal point 6: Navigating adaptation funding mechanisms}

This category is closely related to the previous class of archetypes but focuses on the funding mechanisms themselves. It has distinct underlying factors and includes only one archetype, which we named Restrictions, Conditions, and Eligibility Criteria, or the Eligibility archetype. This archetype is technical, institutional, and political in nature and is focused on the minute details of a particular funding mechanism. It involves lack of clarity on what the eligibility criteria of certain grants are or simply not meeting them. Many mentioned how difficult to understand and onerous to complete grant applications are. Even grants aimed at lower capacity communities may be so restrictive than many cannot meet the eligibility criteria. Suggested interventions to address this archetype include adding adaptation criteria to existing funding streams; establishing a pool of matching funds that smaller communities could draw on; integrating different local 
planning processes and documents to create efficiencies; and updating local codes and standards so that certain funding sources can be used for adaptation.

\section{Focal point 7: Having or building capacity to use and administer adaptation funds}

The final class relates to local communities' ability to use and administer funds. We view it as a variation of the Lack of Capacity archetype, as it has the same underlying drivers and is similar in nature, but it has a distinct effect and therefore is treated as a separate archetype. Many workshop participants pointed out that even if communities successfully apply for funding, it takes a particular kind of qualification and capacity to administer the received funds. Some lower capacity communities may not bother to apply, if they do not meet required accounting standards, or simply do not have the staff capacity to manage multiple or even few but bigger and complex grants. Sometimes, communities also cannot use available grant funding during a specified grant period and must return unspent funds. Possible solutions to this archetypal challenge include establishing or working with capable lead organizations, trainings in grant administration, or building up staff capacity through capacity and block grants.

\section{DISCUSSION AND CONCLUSION}

In this paper, we looked beneath the surface of the often-heard complaint that "we just don't have enough money" to implement adaptation actions. The financing archetypes introduced here are used as a shorthand to describe repeatedly found patterns of finance challenges, driven by interlocking factors, e.g., institutional, human, political, or economic, that mutually reinforce each other and that have distinct consequences for local governments' ability to raise the necessary funds to advance adaptation. Uncovering these archetypes constitutes an important advance in understanding: rather than merely cataloguing barriers as isolated phenomena, this study answers the call for more explanatory research into barriers (Eisenack et al. 2014, Biesbroek et al. 2017). Exploring the causal forces underlying finance challenges in detail reveals greater opportunities for intervention. In our view, this is particularly critical in diverse contexts where one-size solutions cannot adequately address real-world problems yet where pragmatic advances are urgently needed. The many concrete suggestions generated by workshop participants begin to chart ways forward (more details in Appendix 2).

One of the surprising findings of the study is how similar the archetypal finance challenges are across types of local communities, geographic contexts, and sectoral concerns. By this, we do not mean to say that the size of the funding gap is the same everywhere. Adaptation in highly urbanized environments may well cost more than in rural areas (although funding needs and gaps are yet to be established comprehensively). But nearly all archetypes were found in coastal and inland areas, in southern as much as in northern parts of the state. Different funding streams may be available (or lacking) in different sectors but the archetypes of establishing adaptation as a priority, making the economic case, building the capacity of the funding seeker, and so on emerged in each context.

Another important insight from this analysis is that addressing any one archetype alone, in the hopes of having found the "silver bullet" solution, will not address the deep-seated finance challenges uncovered in this study. For example, the elegant, albeit elusive solution of "simply providing more funding" to local governments, while absolutely critical, will not by itself be enough. If there is no capacity to apply for funding or no capacity to administer funds, making more funds available, which remain beyond reach, will not solve the problem. The nearly exclusive focus on generating new funding vehicles, while a commendable step, by itself will likewise not fill the adaptation funding gap.

Another key finding from the study is to heed special caution with "solutions" that reinforce long-standing injustices and disparities. For example, innovative funding mechanisms and private sector actors entering the adaptation arena will bring welcome change for some and aggravate an already difficult and complex problem for others. Thus, where investors wish to develop new funding vehicles, these efforts must be combined with systemic, comprehensive, and sustained capacity building efforts oriented toward lower capacity communities, lest it reinforce historical patterns of privilege. Similarly, the highly commendable idea of providing a one-stop funding information clearinghouse (as is being developed in California ${ }^{[6]}$ ) which helps to resolve one of the archetypes, may well backfire without additional interventions: many more people will be aware of limited funding sources and by applying for them inadvertently increase the competition and opportunity cost, i.e., the time spent applying for grants, but if the success rate and funding amounts stay the same, the clearinghouse alone will not necessarily help local communities get more funding.

The adaptation finance archetypes identified in this study reflect the state of adaptation at the local level in California at this time; they can be expected to change in importance over time; they may improve or worsen, e.g., funding shortfalls for planning acutely felt now, may be magnified as more communities move toward implementation. In fact, a repeat investigation of these archetypes in other places and several years from now may be a way to confirm their validity and measure adaptation progress over time.

Finally, our archetype analysis suggests that any one actor, local, state, federal, philanthropic, or private, cannot make sufficient progress alone. Given the multifactorial and often highly institutionalized causes underlying any one archetype, sustained partnerships and coordination of multiple actions will be needed to make a lasting difference. Accelerating climate change and associated impacts will require such collaboration. Comprehensive and complementary sets of interventions may have a better chance at affecting long-standing patterns of thinking, habitual behavior, organizational silos, rules, and regulations. This suggests that funders and investors must come together to better coordinate their interests and efforts. We see significant opportunity for local, regional, state, federal, and philanthropic actors to create the conditions together that will allow a much broader set of communities to enter the adaptation process and garner the necessary resources to create a safe and dignified future.

${ }^{[1]}$ Examples to support this interaction can be found at re:focus partners (http://www.refocuspartners.com/) and the Center for Community Investment (https://centerforcommunityinvestment. org/). 
${ }^{[2]}$ SB 379 (2015), Jackson. Land use: general plan: safety element. See: https://leginfo.legislature.ca.gov/faces/billNavClient.xhtml? bill id=201520160SB379.

SB 1 (2017), Beall. Transportation funding. The bill provides "starter funding" for adaptation (up to \$20 million) to local and regional agencies for adaptation planning). See: https://leginfo. legislature.ca.gov/faces/billNavClient.xhtml?bill id=201720180SB1, Section 9.

SB 628 (2013) Beall. Enhanced infrastructure financing districts (EIFD). See: https://leginfo.legislature.ca.gov/faces/billTextClient. xhtml?bill id=201320140SB628.

${ }^{[3]}$ SB 246, Wieckowski (2015). Climate change adaptation. See: https://leginfo.legislature.ca.gov/faces/billTextClient.xhtml?

bill id=201520160SB246.

[4] The other half of the workshop was dedicated to questions related to a sister project on organizational capacities for adaptation, which are presented in Kay et al. (2018).

[5] Voters passed Proposition 13 in 1978; see: https://www. californiataxdata.com/pdf/Prop13.pdf.

[6] See the California Adaptation Clearinghouse at: https:// resilientca.org/

Responses to this article can be read online at:

http://www.ecologyandsociety.org/issues/responses. php/10980

\section{Acknowledgments:}

The research team would like to thank the California Natural Resources Agency (CNRA) for funding support for this project and Jamie Anderson, DWR, and Michael McCormick, Office of Planning and Research (OPR) for advice along the way. The research would not have been possible without the workshop participants and survey respondents who gave generously of their time to share their experience of adaptation finance-related challenges. Several individuals assisted this project at various points and we appreciate each and every one's contributions, including the workshop note takers and those providing space for the events. Rob Kay, Brenda Dix, Maya Bruguera, and Hannah Wagner (all ICF) contributed critical support on project management, the survey, and literature review; Kif Scheuer ( $L G C$ ) helped with the workshop facilitation and overall thinking. The work reported here was sponsored by the California Natural Resources Agency and administered by the University of California-Berkeley Energy and Climate Institute. It does not necessarily represent the views of the Natural Resources Agency, its employees, or the State of California. In addition, J.E.'s time on this project was partially supported by USEPA grant number 83519401. Its contents are solely the responsibility of the grantee and do not necessarily represent the official views of the USEPA. The EPA grant and ICF helped with publication fees and we thank them for helping to make this paper open access.

\section{LITERATURE CITED}

AGF. 2010. Report of the Secretary General's High-level Advisory Group on climate change financing. United Nations, New York, New York, USA.
Aylett, A. 2014. Progress and challenges in the urban governance of climate change: results of a global survey. MIT, Cambridge, Massachusetts, USA.

Barnard, S. 2015. Climate finance for cities: How can international climate funds best support low-carbon and climate resilient urban development? Overseas Development Institute, London, UK. [online] URL: https://www.odi.org/sites/odi.org.uk/files/odiassets/publications-opinion-files/9660.pdf

Barrett, S. 2013. Local level climate justice? Adaptation finance and vulnerability reduction. Global Environmental Change 23 (6):1819-1829. https://doi.org/10.1016/j.gloenvcha.2013.07.015

Barrett, S. 2014. Subnational climate justice? Adaptation finance distribution and climate vulnerability. World Development 58:130-142. https://doi.org/10.1016/j.worlddev.2014.01.014

Bedsworth, L. W., and E. Hanak. 2013. Climate policy at the local level: insights from California. Global Environmental Change 23 (3):664-677. https://doi.org/10.1016/j.gloenvcha.2013.02.004

Bendandi, B., and P. Pauw. 2016. Remittances for adaptation: an 'alternative source' of international climate finance? Pages 195-211 in A. Milan, B. Schraven, K. Warner, and N. Cascone, editors. Migration, risk management and climate change: evidence and policy responses. Springer International, Heidelberg, Germany. https://doi.org/10.1007/978-3-319-42922-9 10

Bierbaum, R., A. Lee, J. Smith, M. Blair, L. M. Carter, F. S. Chapin III, P. Fleming, S. Ruffo, S. McNeeley, M. Stults, L. Verduzco, and E. Seyller. 2014. Adaptation. Pages 670-706 in J. M. Melillo, T. T. C. Richmond, and G. W. Yohe, editors. Climate change impacts in the United States: the third national climate assessment. U.S. Global Change Research Program, Washington, D.C., USA. https://doi.org/10.7930/j07h1ggt

Biesbroek, R., J. Dupuis, A. Jordan, A. Wellstead, M. Howlett, P. Cairney, J. Rayner, and D. Davidson. 2015. Opening up the black box of adaptation decision-making. Nature Climate Change 5:493-494. https://doi.org/10.1038/nclimate2615

Biesbroek, R., J. Dupuis, and A. Wellstead. 2017. Explaining through causal mechanisms: resilience and governance of socialecological systems. Current Opinion in Environmental Sustainability 28:64-70. https://doi.org/10.1016/j.cosust.2017.08.007

Blaikie, P. 1985. The political economy of soil erosion in developing countries. Longman, New York, New York, USA.

Build America Investment Initiative. 2015. Federal resource guide for infrastructure planning and design. Build America Investment Initiative, Washington, D.C., USA.

Carmin, J., N. Nadkarni, and C. Rhie. 2012. Progress and challenges in urban climate adaptation planning: results of a global survey. MIT, Cambridge, Massachusetts, USA.

Coffee, J. 2016. Let's create a climate adaptation opportunity standard to catalyze investors. Climate Resilience Consulting, Chicago, Illinois, USA. [online] URL: https://www. climateresilienceconsulting.com/blog/759

Cumming, G. S. 2016. Heterarchies: reconciling networks and hierarchies. Trends in Ecology \& Evolution 31(8):622-632. https:// doi.org/10.1016/j.tree.2016.04.009 
Cundill, G., G. S. Cumming, D. Biggs, and C. Fabricius. 2012. Soft systems thinking and social learning for adaptive management. Conservation Biology 26(1):13-20. https://doi. org/10.1111/j.1523-1739.2011.01755.X

Dangerman, A. T. C. J., and H.-J. Schellnhuber. 2013. Energy systems transformation. Proceedings of the National Academy of Sciences 110(7):E549-E558. https://doi.org/10.1073/pnas.1219791110

Eakin, H., R. DeFries, S. Kerr, E. F. Lambin, J. Liu, P. J. Marcotullio, P. Messerli, A. Reenberg, X. Rueda, S. R. Swaffield, B. Wicke, and K. Zimmerer. 2014. Significance of telecoupling for exploration of land-use change. Pages 141-161 in K. C. Seto and A. Reenberg, editors. Rethinking global land use in an urban era. MIT Press, Cambridge, Massachusetts, USA. https://doi. org/10.7551/mitpress/9780262026901.003.0008

Eisenack, K. 2012. Archetypes of adaptation to climate change. Pages 107-122 in M. Glaser, G. Krause, B. M. W. Ratter, and M. Welp, editors. Human-nature interactions in the Anthropocene: potentials of social-ecological systems analysis. Routledge, New York, New York, USA. https://doi.org/10.4324/9780203123195

Eisenack, K., S. C. Moser, E. Hoffmann, R. J. T. Klein, C. Oberlack, A. Pechan, M. Rotter and C. J. A. M. Termeer. 2014. Explaining and overcoming barriers to climate change adaptation. Nature Climate Change 4:867-872. https://doi. org/10.1038/nclimate2350

Eisenack, K., S. Villamayor-Tomas, G. Epstein, C. Kimmich, N. Magliocca, D. Manuel-Navarrete, C. Oberlack, M. Roggero, and D. Sietz. 2019. Design and quality criteria for archetype analysis. Ecology and Society, in press.

Ekstrom, J. A., L. W. Bedsworth, and A. Fencl. 2017. Gauging climate preparedness to inform adaptation needs: local level adaptation in drinking water quality in CA, USA. Climatic Change 140(3-4):467-481. https://doi.org/10.1007/s10584-016-1870-3

European Commission. 2013. Climate change adaptation practice across the EU: understanding the challenges and ways forward in the context of multi-level governance. EU Publications Office, Brussels, Belgium.

Finzi Hart, J. A., P. M. Grifman, S. C. Moser, A. Abeles, M. R. Myers, S. C. Schlosser, and J. A. Ekstrom. 2012. Rising to the challenge: results of the 2011 coastal California adaptation needs assessment. University of Southern California Sea Grant Program, Los Angeles, California, USA.

Glaser, B. G., and A. L. Strauss. 2011. The discovery of grounded theory: strategies for qualitative research. Routledge, New York, New York, USA. https://doi.org/10.4324/9780203793206

Jäger, J., M. D. A. Rounsevell, P. A. Harrison, I. Omann, R. Dunford, M. Kammerlander, and G. Pataki. 2015. Assessing policy robustness of climate change adaptation measures across sectors and scenarios. Climatic Change 128(3-4):395-407. https:// doi.org/10.1007/s10584-014-1240-y

Kasperson, J. X., R. E. Kasperson, and B. L. Turner II, editors. 1995. Regions at risk: comparisons of threatened environments. United Nations University Press, Tokyo, Japan.

Kay, R., K. Scheuer, B. Dix, M. Bruguera, A. Wong, and J. Kim. 2018. Overcoming organizational barriers to implementing local government adaptation strategies. Publication number: CNRACCA4-2018-005. California's Fourth Climate Change Assessment, California Natural Resources Agency, Sacramento, California, USA.

Keohane, R. O., and E. Ostrom, editors. 1995. Local commons and global interdependence: heterogeneity and cooperation in two domains. Sage, London, UK. https://doi.org/10.4135/9781446222010

Kim, D. H. 1992. System archetypes I: diagnosing systemic issues and designing high-leverage interventions. Pegasus Communications, Waltham, Massachusetts, USA.

Kimmich, C. 2013. Linking action situations: coordination, conflicts, and evolution in electricity provision for irrigation in Andhra Pradesh, India. Ecological Economics 90(Supplement C):150-158. https://doi.org/10.1016/i.ecolecon.2013.03.017

Kimmich, C., and S. V. Tomas. 2019. Assessing action situation networks: a configurational perspective on water and energy governance in irrigation systems. Water Economics and Policy 5 (1):1850005. https://doi.org/10.1142/S2382624X18500054

Klein, R. J. T., G. F. Midgley, B. L. Preston, M. Alam, F. G. H. Berkhout, K. Dow, and M. R. Shaw. 2014. Adaptation opportunities, constraints, and limits. Pages 899-943 in C. B. Field, V. R. Barros, D. J. Dokken, K. J. Mach, M. D. Mastrandrea, T. E. Bilir, M. Chatterjee, K. L. Ebi, Y. O. Estrada, R. C. Genova, B. Girma, E. S. Kissel, A. N. Levy, S. MacCracken, P. R. Mastrandrea and L. L. White, editors. Climate change 2014: impacts, adaptation, and vulnerability. Part A: global and sectoral aspects. Contribution of Working Group II to the Fifth Assessment Report of the Intergovernmental Panel on Climate Change. Cambridge University Press, Cambridge, UK. https://doi. org/10.1017/cbo9781107415379.021

Kok, M., M. Lüdeke, P. Lucas, T. Sterzel, C. Walther, P. Janssen, D. Sietz, and I. de Soysa. 2016. A new method for analysing socioecological patterns of vulnerability. Regional Environmental Change 16(1):229-243. https://doi.org/10.1007/s10113-014-0746-1

Levers, C., D. Müller, K. Erb, H. Haberl, M. R. Jepsen, M. J. Metzger, P. Meyfroidt, T. Plieninger, C. Plutzar, J. Stürck, P. H. Verburg, P. J. Verkerk, and T. Kuemmerle. 2018. Archetypical patterns and trajectories of land systems in Europe. Regional Environmental Change 18(3):715-732. https://doi.org/10.1007/ s10113-015-0907-X

Lüdeke, M. K. B., G. Petschel-Held, and H.-J. Schellnhuber. 2004. Syndromes of global change: the first panoramic view. GAIA Ecological Perspectives for Science and Society 13(1):42-49. https://doi.org/10.14512/gaia.13.1.10

McGinnis, M. D. 2011. Networks of adjacent action situations in polycentric governance. Policy Studies Journal 39(1):51-78. https://doi.org/10.1111/j.1541-0072.2010.00396.x

Meadows, D. 1999. Leverage points: places to intervene in a system. Sustainability Institute Papers. Sustainability Institute, Hartland, Vermont, USA.

Measham, T. G., B. L. Preston, T. F. Smith, C. Brooke, R. Gorddard, G. Withycombe, and C. Morrison. 2011. Adapting to climate change through local municipal planning: barriers and challenges. Mitigation and Adaptation Strategies for Global Change 16(8):889-909. https://doi.org/10.1007/s11027-011-9301-2 
Messerli, P., M. Giger, M. B. Dwyer, T. Breu, and S. Eckert. 2014. The geography of large-scale land acquisitions: analysing socioecological patterns of target contexts in the Global South. Applied Geography 53:449-459. https://doi.org/10.1016/j.apgeog.2014.07.005

Moser, S. C. 2007. Is California preparing for sea-level rise? The answer is disquieting. California Coast and Ocean 22(4):24-30.

Moser, S. C. 2009. Whether our levers are long enough and the fulcrum strong? Exploring the soft underbelly of adaptation decisions and actions. Pages 313-343 in W. N. Adger, I. Lorenzoni, and K. O'Brien, editors. Adapting to climate change: thresholds, values, governance. Cambridge University Press, Cambridge, UK. https://doi.org/10.1017/CBO9780511596667.021

Moser, S. C., J. Coffee, and A. Seville. 2017. Rising to the challenge, together. The Kresge Foundation, Troy, Michigan, USA. [online] URL: https://kresge.org/content/rising-challenge-together

Moser, S. C., and J. A. Ekstrom. 2010. A framework to diagnose barriers to climate change adaptation. Proceedings of the National Academy of Sciences of the United States of America 107 (51):22026-22031. https://doi.org/10.1073/pnas.1007887107

Moser, S. C., and J. A. Ekstrom. 2012. Identifying and overcoming barriers to climate change adaptation in San Francisco Bay: results from case studies. CEC-500-2012-034. California Energy Commission, Sacramento, California, USA.

Moser, S. C., J. A. Ekstrom, J. Kim, and S. Heintsch. $2018 a$. Adaptation finance challenges: characteristic patterns facing California local governments and ways to overcome them. Publication number: CCCA4-CNRA-2018-007. California's Fourth Climate Change Assessment, California Natural Resources Agency, Sacramento, California, USA. [online] URL: http://www.climateassessment.ca.gov/techreports/governance.html

Moser, S. C., J. A. Finzi Hart, A. Newton Mann, N. Sadrpour, and P. M. Grifman. 2018b. Growing effort, growing challenge: findings from the 2016 CA Coastal Adaptation Needs Assessment Survey. Publication number: CCCA4-EXT-2018-009. California's Fourth Climate Change Assessment, California Natural Resources Agency, Sacramento, California, USA.

NHA Advisors. 2017. Finance guide for resilient by design Bay Area challenge design teams. Final Version 1.0. NHA Advisors, San Rafael, California, USA.

Nhamo, G., and S. Nhamo. 2016. Paris (COP21) Agreement: loss and damage, adaptation and climate finance issues. International Journal of African Renaissance Studies 11(2):118-138. https://doi. org/10.1080/18186874.2016.1212479

Oberlack, C. 2017. Diagnosing institutional barriers and opportunities for adaptation to climate change. Mitigation and Adaptation Strategies for Global Change 22(5):805-838. https:// doi.org/10.1007/s11027-015-9699-z

Oberlack, C., and K. Eisenack. 2014. Alleviating barriers to urban climate change adaptation through international cooperation. Global Environmental Change 24:349-362. https://doi.org/10.1016/ j.gloenvcha.2013.08.016

Oberlack, C., and K. Eisenack. 2018. Archetypical barriers to adapting water governance in river basins to climate change.
Journal of Institutional Economics 14:527-555. https://doi. org/10.1017/S1744137417000509

Oberlack, C., D. Sietz, E. Bürgi-Bonanomi, A. de Bremond, J. Dell'Angelo, K. Eisenack, E. Ellis, G. Epstein, M. Giger, A. Heinimann, C. Kimmich, M. T. J. Kok, D. Manuel-Navarrete, P. Messerli, P. Meyfroidt, T. Václavík, and S. Villamayor-Tomás. 2019. Archetype analysis in sustainability research: meanings, motivations, and evidence-based policy making. Ecology and Society 24(2):26. https://doi.org/10.5751/ES-10747-240226

Oberlack, C., L. Tejada, P. Messerli, S. Rist, and M. Giger. 2016. Sustainable livelihoods in the global land rush? Archetypes of livelihood vulnerability and sustainability potentials. Global Environmental Change 41(Supplement C):153-171. https://doi. org/10.1016/j.gloenvcha.2016.10.001

Organisation for Economic Co-operation and Development (OECD) and Bloomberg Philanthropies. 2014. Cities and climate change: national governments enabling local action. OECD Policy Perspectives. OECD, Paris, France. [online] URL: http:// www.oecd.org/env/cc/Cities-and-climate-change-2014-Policy-PerspectivesFinal-web.pdf

Ostrom, E. 1990. Governing the commons: the evolution of institutions for collective action. Cambridge University Press, Cambridge, UK.

Pauw, W. P. 2017. Mobilising private adaptation finance: developed country perspectives. International Environmental Agreements: Politics, Law and Economics 17(1):55-71. https://doi. org/10.1007/s10784-016-9342-9

Petschel-Held, G., A. Block, M. Cassel-Gintz, J. Kropp, M. K. B. Lüdeke, O. Moldenhauer, F. Reusswig, and H.-J. Schellnhuber. 1999. Syndromes of global change: a qualitative modelling approach to assist global environmental management. Environmental Modeling and Assessment 4:295-314. https://doi. org/10.1023/A:1019080704864

Proust, K., B. Newell, H. Brown, A. Capon, C. Browne, A. Burton, J. Dixon, L. Mu, and M. Zarafu. 2012. Human health and climate change: leverage points for adaptation in urban environments. International Journal of Environmental Research and Public Health 9(6):2134-2158. https://doi.org/10.3390/ ijerph9062134

re:focus partners. 2015. Levering catastrophe bonds as a mechanism for resilient infrastructure project finance. re:focus partners. [online] URL: http://www.refocuspartners.com/wpcontent/uploads/2017/02/RE.bound-Program-Report-December-2015. pdf

re:focus partners. 2017. A guide for public-sector resilience bond sponsorship. re:focus partners. [online] URL: http://www. refocuspartners.com/wp-content/uploads/pdf/RE.bound-ProgramReport-September-2017.pdf

Robinson, S. A., and M. Dornan. 2017. International financing for climate change adaptation in small island developing states. Regional Environmental Change 17(4):1103-1115. https://doi. org/10.1007/s10113-016-1085-1

Schellnhuber, H.-J., A. Block, M. Cassel-Gintz, J. Kropp, G. Lammel, W. Lass, R. Lienenkamp, C. Loose, M. K. B. Lüdeke, 
O. Moldenhauer, G. Petschel-Held, M. Plöchl, and F. Reusswig. 1997. Syndromes of global change. GAIA - Ecological Perspectives for Science and Society 6(1):18-33. https://doi. org/10.14512/gaia.6.1.4

Sietz, D., M. K. B. Lüdeke, and C. Walther. 2011. Categorisation of typical vulnerability patterns in global drylands. Global Environmental Change 21(2):431-440. https://doi.org/10.1016/j. gloenvcha.2010.11.005

Sietz, D., J. C. Ordoñez, M. T. J. Kok, P. Janssen, H. B. M. Hilderink, P. Tittonell, and H. V. Dijk. 2017. Nested archetypes of vulnerability in African drylands: where lies potential for sustainable agricultural intensification? Environmental Research Letters 12(9):095006. https://doi.org/10.1088/1748-9326/aa768b

Smith, J. B., T. Dickinson, J. D. B. Donahue, I. Burton, E. Haites, R. J. T. Klein and A. Patwardhan. 2011. Development and climate change adaptation funding: coordination and integration. Climate Policy 11(3):987-1000. https://doi.org/10.1080/1469306$\underline{2.2011 .582385}$

Sovacool, B. K., B. O. Linnér, and R. J. T. Klein. 2017. Climate change adaptation and the Least Developed Countries Fund (LDCF): qualitative insights from policy implementation in the Asia-Pacific. Climatic Change 140(2):209-226. https://doi. org/10.1007/s10584-016-1839-2

Srinivasan, V., E. F. Lambin, S. M. Gorelick, B. H. Thompson, and S. Rozelle. 2012. The nature and causes of the global water crisis: syndromes from a meta-analysis of coupled human-water studies. Water Resources Research 48:W10516. https://doi. org/10.1029/2011WR011087

Trabacchi, C., and F. Mazza. 2015. Emerging solutions to drive private investment in climate resilience. CPI Working Paper. Climate Policy Initiative, San Francisco, California, USA. [online] URL: https://climatepolicyinitiative.org/wp-content/uploads/2015/06/ Finance-for-Climate-Resilience.pdf

United Nations Environment Programme (UNEP). 2007. Vulnerability of people and the environment: challenges and opportunities. Background Report on Chapter 7 of the Fourth Global Environment Outlook (GEO-4). UNEP, Nairobi, Kenya, and Netherlands Environmental Assessment Agency, The Hague, The Netherlands.

United Nations Framework Convention on Climate Change (UNFCCC). 2008. Investment and financial flows to address cliamte change: an update. FCCC/TP/2008/7. UNFCCC, Geneva, Switzerland.

United Nations Global Compact, UN Framework Convention on Climate Change (UNFCCC), and Environment Programme (UNEP). 2015. The business case for responsible corporate adaptation: strengthening private sector and community resilience. A care for climate report by the UN Global Compact, UNFCCC, and UNEP Finance Initiative, CEO Water Mandate, Oxfam, ARISE, World Resources Institute, UNEP, UNEP DTU Partnership, CDP, Four Twenty Seven, Rainforest Alliance, University of Notre Dame Global Adaptation Index. UN, New York, New York, USA.

Václavík, T., S. Lautenbach, T. Kuemmerle, and R. Seppelt. 2013. Mapping global land system archetypes. Global Environmental Change 23(6):1637-1647. https://doi.org/10.1016/j.gloenvcha.2013.09.004
Walsh, I., J. A. Holton, L. Bailyn, W. Fernandez, N. Levina, and B. Glaser. 2015. What grounded theory is: a critically reflective conversation among scholars. Organizational Research Methods 18(4):581-599. https://doi.org/10.1177/1094428114565028

Webber, S. 2013. Performative vulnerability: climate change adaptation policies and financing in Kiribati. Environment and Planning A: Economy and Space 45(11):2717-2733. https://doi. org/10.1068/a45311

Zimring, M., E. Hallstein, L. Blumberg, M. Kiparsky, and J. Downing. 2015. New prospects for financing natural infrastructure. A TNC White Paper. The Nature Conservancy of California, San Francisco, California, USA. 
Appendix 1. Research methods.

\section{Survey}

\section{Survey Questions}

We developed a survey to collect background and contextual information for the stakeholder workshops described below, but more broadly to gain insights about adaptation efforts by local government entities in California. The survey contained 19 questions; most of them involved simple nominal or rating questions. Six questions focused on demographics; five were about climate change adaptation more generally, including a broad set of barriers to adaptation; the remaining eight questions were focused on funding and financing adaptation. Detailed results on all survey questions is available in Moser et al. 2018)

Question 1: Please indicate whether you work with or serve a city or county. This is not for identification purposes, but to collate survey responses by region. (Multiple choice question)

Question 2: Please indicate the city or county you work with or serve. This is not for identification purposes, but to collate survey responses by region. (Multiple choice question)

Question 3: Please indicate the type of entity in which you work. If you work across multiple sectors, please choose the one that best matches your primary work responsibility. (Multiple choice question; Please select only one answer.)

Question 4: Please indicate what type of position you hold in your organization. (Multiple choice question)

Question 5: What is the approximate size of the city or county you serve? (Multiple choice question)

Question 6: Do you currently actively participate in coordinated adaptation efforts in your region (i.e., through the Alliance of Regional Collaboratives for Climate Adaptation or another network)? (Multiple choice question)

Question 7: If you participate in the discussions of a regional adaptation collaborative or network, please indicate which one. (Write-in question)

Question 8: Which category best describes your current phase of climate change adaptation/ preparedness/resilience planning and implementation? (Select only one option that comes closest to your current level of activity.) (Multiple choice question)

Question 9: Whether or not your organization has already taken action to prepare for the possible impacts of climate change, how much of a hurdle has each of the following issues been in your efforts to date or do you anticipate it to be? (Rating question)

Question 10: Can you share how you overcame the barriers you encountered, or provide 1-2 creative ideas for overcoming these barriers? (Write-in question) 
Question 11: We are interested in how your jurisdiction finances climate adaptation/ preparedness action. Over the past 2 years, has your jurisdiction spent money on any aspect of climate adaptation/preparedness/resilience building? (Multiple choice question)

Question 12: If in the last 2 years you have invested in climate adaptation/preparedness/ resilience building, please list the type of actions and processes you have spent money on (check all that apply). (Multiple choice question)

Question 13: For the activities you checked in Question 12, what sources of funding did you use (please check all that apply). (Multiple choice question)

Question 14: In the next 5 years, for which areas of climate change adaptation/ preparedness/resilience building do you expect to need additional funds? (check all that apply). (Multiple choice question)

Question 15: Please indicate the status of your fund-raising efforts for the activities listed in Question 14 (select the option that best describes the current status). (Multiple choice question)

Question 16: To date, when attempting to acquire funds to finance adaptation-related activities, which challenges have you encountered (check all that apply). (Multiple choice question)

Question 17: If you have successfully obtained funds to finance adaptation-related activities, how have you overcome the above-mentioned challenges (please check all that apply). (Multiple choice question)

Question 18: Please share any additional thoughts you might have about financial or institutional barriers that were not covered in the questions above. We welcome your thoughts and insights. (Write-in question)

Question 19: Please provide your name and email below if you're willing to be contacted about follow-up questions. Your responses will be kept confidential. (Write-in question)

\section{Sampling and Survey Duration}

The link to the online survey was distributed through several listservs, email contact lists for the Alliance of Regional Collaboratives for Climate Adaptation (ARCCA) ${ }^{1}$, the Local Government Commission (LGC), and to attendees of the Second California Adaptation Forum (CAF, Long Beach, September 7-8, 2016). It was also shared via a project website set up by LGC and at the California Climate Science Symposium (January 25-26, 2017) to reach the widest distribution, rather than specifically representing a bounded population. Reminders were repeatedly sent to contact lists to which the research team had ready access. The survey was open to respondents for a 13-month period from June 28, 2016 and July 27, 2017. Participation in the survey was not tied in an obligatory sense to participation in any other part of the study. Due to the distribution (sampling) method, we cannot construct a response rate. Instead, the responses create a non-parametric dataset, i.e., neither the data, nor its summary statistics, provide a representative sample of all local governments in California. In other words, if we report that $\mathrm{x} \%$ of

\footnotetext{
${ }^{1}$ ARCCA is a network of regional collaboratives from across California. The Local Government Commission (https://www.lgc.org/) serves as its coordinator. Each collaborative, and the statewide network of regional collaboratives, aims to advance adaptation statewide and increase local capacity to build community resilience (see http://arccacalifornia.org).
} 
respondents from local governments expressed that funding climate adaptation is the main hurdle impeding their planning for climate change impacts, it does not necessarily allow us to conclude that that same $\mathrm{x} \%$ of all local governments in California share that view.

\section{Criteria for Data Inclusion}

Survey questions were optional, so that for any given question a participant could skip to the next question without having to answer the previous question. This typically creates a lower response rate per question but can also help prevent early drop-off from potentially frustrated respondents when they want to get through the survey more quickly (Dillman et al. 2009). As with any survey dataset, we reviewed the dataset to identify and eliminate those that did not meet our standards.

The criteria required for inclusion are as follows:

- Respondents must have answered one or more substance question, beyond the question of "do you collaborate...?", thus fulfilling the criteria of being a partial or complete survey.

- Repeat respondents must have not already submitted a survey that met criteria \#1.

We collected a total of 333 online survey responses, of which 251 met Criterion \#1, i.e. respondents answered at least one substantive question. Criterion \#2 implied that those responses associated with the same name and/or email address were removed if there was a prior complete or partial response associated with the same name and/or email address. The earliest dated eligible response was kept as part of the final dataset.

As a result, of the 251 acceptable responses, 18 were omitted from the analysis because they were identified as duplicates submitted by individuals on different occasions. The remaining 233 responses (70\% of surveys started) were used in the statistical analysis. When discussing results, the questionspecific number of respondents $(\mathrm{N})$ is included, given that not all respondents answered every question.

\section{Potential Biases in the Sample}

There are 482 municipalities and 58 counties, for a total of 540 local governments in California. We received 233 valid survey responses, 173 respondents (or 74\%) of which work for or with a city or county. Thus, we can assume to have captured a good proportion of local governments across the state. It is likely, however, that these responses are biased toward those more interested in and already working in one way or another - on climate change adaptation, with fewer respondents who do not yet engage on this topic.

To better characterize our sample of responses and assess the potential for generalizability absent a known response rate, we compared the geo-location of respondents to the geographical distribution of cities and counties across the state. Table A1.1 and

Table A1.2 (see corresponding Figures in Appendix A, A.2 and A.3) compare the representation of cities and counties, respectively according to size. They show that our survey sample under-represents small cities and counties and overrepresents large cities and counties. Only mid-sized cities are comparable in representation. This might indirectly confirm our suspicion that the survey might be biased toward respondents who are interested and engaged in climate change adaptation, possibly due to the more liberal leanings of larger urban settings or due to greater capacity to address adaptation. 
Table A1.1: Distribution of California cities by size (based on US Census 2012) and of respondents' locations (based on reported affiliated city size)

\begin{tabular}{|l|c|c|c|c|}
\hline Size of cities & $\begin{array}{c}\text { Number of cities } \\
\text { in CA (N=459) }\end{array}$ & $\begin{array}{c}\text { Percent of total } \\
\text { in California }\end{array}$ & $\begin{array}{c}\text { Number of city } \\
\text { respondents in } \\
\text { survey (N=90) }\end{array}$ & $\begin{array}{c}\text { Percent of city } \\
\text { respondents in } \\
\text { survey }\end{array}$ \\
\hline$<25,000$ & 200 & $44 \%$ & 17 & $19 \%$ \\
\hline$>25,000-50,000$ & 90 & $20 \%$ & 11 & $12 \%$ \\
\hline$>50,000-100,000$ & 101 & $22 \%$ & 22 & $24 \%$ \\
\hline$>100,000-500,000$ & 63 & $14 \%$ & 32 & $36 \%$ \\
\hline$>500,000$ & 5 & $1 \%$ & 8 & $9 \%$ \\
\hline
\end{tabular}

Source: The Authors

Table A1.2: Distribution of California counties by size (based on US Census 2012) and of respondents' locations (based on reported affiliated county size)

\begin{tabular}{|l|c|c|c|c|}
\hline Size of counties & $\begin{array}{c}\text { Number of } \\
\text { counties in CA } \\
(\mathbf{N = 5 8 )}\end{array}$ & $\begin{array}{c}\text { Percent of total } \\
\text { in California }\end{array}$ & $\begin{array}{c}\text { Number of county } \\
\text { respondents in } \\
\text { survey (N=45) }\end{array}$ & $\begin{array}{c}\text { Percent of county } \\
\text { respondents in } \\
\text { survey }\end{array}$ \\
\hline$<25,000$ & 9 & $16 \%$ & 3 & $7 \%$ \\
\hline$>25,000-50,000$ & 6 & $10 \%$ & 1 & $2 \%$ \\
\hline$>50,000-100,000$ & 8 & $14 \%$ & 2 & $4 \%$ \\
\hline$>100,000-500,000$ & 18 & $31 \%$ & 20 & $44 \%$ \\
\hline$>500,000$ & 17 & $29 \%$ & 19 & $42 \%$ \\
\hline
\end{tabular}

Source: The Authors

As for the similarity of our survey sample in terms of the geographic distribution of respondents across the state, we placed CA cities and counties into the climate regions used in the Fourth Climate Change Assessment $(\mathrm{CCA} 4)^{2}$ and compared the representation in the survey to the statewide distribution based on the US Census. Table A1.3 shows that comparison, illustrating that the proportion of city respondents was similar to proportions across regions statewide. For example, according to the 2012 US Census, $36 \%$ of CA cities are in the Los Angeles climate region and 34\% of our respondents worked with or at cities in the Los Angeles region. Only a few regions are inadequately represented in the survey: for example, the San Joaquin Valley and Inland South are underrepresented, and San Francisco Bay Area is overrepresented in our survey compared to their Census-based prominence.

Table A1.3: Comparison of the Representation of Cities by Climate Region, Statewide and in the Survey

\begin{tabular}{|l|c|c|c|c|}
\hline \multicolumn{1}{|c|}{ CCA4 Regions } & $\begin{array}{c}\text { Number of } \\
\text { cities in CA } \\
\mathbf{( N = 4 5 9 )}\end{array}$ & $\begin{array}{c}\text { Percent of } \\
\text { total cities }\end{array}$ & $\begin{array}{c}\text { Number of city } \\
\text { survey } \\
\text { respondents } \\
(\mathbf{N}=90)\end{array}$ & $\begin{array}{c}\text { Percent of city } \\
\text { survey } \\
\text { respondents }\end{array}$ \\
\hline Central Coast & 33 & $7 \%$ & 9 & $10 \%$ \\
\hline
\end{tabular}

2 To examine responses across regions within California, individual responses were tagged with a regional identifier, based on how respondents answered Question 2 "Please indicate the city or county you work with or serve. This is not for identification purposes, but to collate survey responses by region." The regional identifiers were derived from the climate regions created by the CCA4 team. 


\begin{tabular}{|l|c|c|c|c|}
\hline Inland South & 23 & $5 \%$ & 0 & $0 \%$ \\
\hline Los Angeles & 164 & $36 \%$ & 31 & $34 \%$ \\
\hline North Coast & 23 & $5 \%$ & 3 & $3 \%$ \\
\hline Sacramento Valley & 35 & $8 \%$ & 9 & $10 \%$ \\
\hline San Diego & 18 & $4 \%$ & 7 & $8 \%$ \\
\hline San Francisco Bay Area & 84 & $18 \%$ & 27 & $30 \%$ \\
\hline San Joaquin Valley & 59 & $13 \%$ & 2 & $2 \%$ \\
\hline Sierra Nevada Mountains & 20 & $4 \%$ & 2 & $2 \%$ \\
\hline
\end{tabular}

Source: The Authors

In summary, while we cannot assess the statewide representativeness of our survey sample statistically by providing an assessment of the response rate, we can describe our sample in qualitative ways: it is likely biased toward more adaptation-interested and -engaged respondents, representing local governments across California, but particularly well from larger cities and counties and less well from smaller inland governments. This may well reflect the observation that larger cities are further advanced in their adaptation efforts, and thus more likely to run into finance challenges and thus more interested in the topic of this study.

\section{Workshops, Archetype Analysis and Coding}

\section{Objectives}

The project team held nine stakeholder workshops across the state, with the specific objectives of (1) hearing directly from local government staff and from organizations supporting local government efforts on the financing and institutional barriers cities and counties faced; and (2) discussing and exploring potential strategies to overcome these barriers.

To ensure opportunity for engagement from a wide variety of local governments - big and small; coastal and inland; north, central and south - we convened stakeholders in San Diego, Los Angeles, the Central Coast, the San Francisco Bay Area, the Capitol Region, the Central Valley, the North Coast, and the Sierra Nevada, and in an open workshop (without regional specificity) at the 2016 Third California Adaptation Forum in Long Beach.

\section{Recruitment}

The primary sources from which workshop participants were recruited included ARCCA email contact lists of local government officials and other individuals engaged in adaptation work across the state as well as LGC email lists of local government officials. While the ARCCA contact list is more specific to adaptation, it is more biased toward regions that already have established or emerging regional adaptation collaboratives, whereas the LGC email list is less specific to adaptation but provides better coverage across the state. The research team also sent personal invitations to any collaborators they knew in different regions across the state. 
Workshop participation was open to any local government staff and anyone working with local governments on climate adaptation (e.g., consultants, NGO representatives, State agency personnel). Workshops were not size-restricted, but an online registration process (involving responding to the above described survey) was used to adequately prepare logistics for each event. Participation was uneven across the nine workshops, reflecting the size of interested and engaged individuals in each region. The pattern largely followed regional representation in the survey, with most participants from the major metropolitan regions, those attending the California Adaptation Forum, and fewer participants from other regions. Between the nine workshops, there was a total of 149 participants.

\section{Facilitation}

The half-day workshops were organized into two main sessions. The first of these focused on the adaptation funding challenges, while the second focused on institutional barriers to adaptation (the latter is not further discussed in this report as a separate project report was prepared summarizing that effort; see Kay et al. 2018). The project team served as facilitators.

The more specific aim of the funding-focused part of the workshop was to collect information about (a) the size of the funding and financing gap for California local governments, (b) existing economically and politically feasible financing options available to fill this gap, and (c) the nature of the financing challenges and how they can be overcome. The session aimed to answer these questions by (a) generating as much information as possible about the full range of adaptation funding-related challenges that local governments face and (b) engaging participants in sharing and learning about possible ways to minimize or overcome the financing challenges identified.

The workshop began with an introduction and framing of the session. The team highlighted that the session would focus on funding adaptation and climate change preparedness and resilience building efforts, and that any and all related activities and expenditures could be considered part of the conversation. The team also acknowledged that local governments are at various stages in their adaptation efforts, and will therefore vary in experience, knowledge and need. Due to this variance, the team noted that the session would focus on identifying common funding challenges that participants have encountered in other parts of their work; explore to what extent funding adaptation is similar to these common challenges; and examine what if anything is unique about the challenges around funding adaptation. Furthermore, the team noted that mainstreaming adaptation into other efforts (e.g., hazard mitigation planning and general plan updates) was within the workshop scope. Lastly, the team stressed that the session aimed to have a conversation that delved deeper than the oft-heard complaint that there is not enough money. The workshop aimed to explore whether there are challenges in applying for money, accessing or accepting money, limits on what money can be used for, administering money and so on to determine the exact nature of the finance-related problems participants face.

After the framing and introduction, the team engaged in a brainstorming session. Five "stations" (big notepads on tripods) were set up to explore funding challenges from different perspectives:

- Funding issues by sector (e.g., coastal, vs. wildfire, vs. health);

- Funding issues by stage in the adaptation process (e.g., completing initial assessments, planning, implementing actions or monitoring etc.);

- Funding issues by size of community (e.g., work for/with a smaller community vs. a larger city); 
- Funding issues by type of funding source/instrument (e.g., from a State or federal agency, a foundation grant, or their own general funds; a tax or fee-based source vs. a bond or a grant); and,

- Funding issues that apply to cross-cutting adaptation needs (adaptation-related expenditures, e.g., outreach vs. shovel-ready projects)

Participants were given sticky notes to write down up to three issues that fell into any one of these five categories. They then placed these sticky notes on the corresponding notepads. Discussion circles of participants interested in a particular topic formed around each of the five stations to talk about the ideas generated in the brainstorm. Facilitators guided the sharing and discussion of the nature of the challenges written on the sticky notes. Any additional issues identified during the discussion circle were documented on a sticky note and added to the board. Participants then were asked to rotate to another station of interest, and another round of discussion deepened the understanding of the issues raised. Detailed notes were taken by pre-assigned note takers during these rounds of discussion.

Participants then reunited into the big workshop group, and facilitators led a debrief, focusing on the most difficult and complicated issues, the most common issues, and notable insights from the discussion circles. Facilitators also probed further with questions about how funding challenges have been overcome, how foundations, State and federal governments, and others can facilitate overcoming the challenges, what other support would be helpful, and any other ideas. Again, detailed notes were taken by preassigned note takers.

\section{Archetype Analysis}

The majority of available examples of archetype analysis are either expert elicitations or theory-driven (deductive) quantitative meta-analyses of existing case studies. Such studies typically involve elaborate searches for qualifying case studies, extensive coding of eligible studies or identification of quantifiable indicators, followed by qualitative or quantitative analyses of the information such as cluster analysis, principle component analysis, qualitative comparison analysis or fuzzy logic modelling to derive common patterns of associated factors that constitute the archetypes.

These approaches were deemed not applicable to generating a first understanding of the persistent patterns of adaptation finance challenges experienced by local governments in California. Our goal was to identify/discern the (repeated) causal connections made by workshop participants, not to conduct an objective systems analysis or a theoretically-ideologically driven analysis. ${ }^{3} \mathrm{We}$ aimed to understand, synthesize and systematize stakeholders' understanding of the finance challenges they face. Thus, after the conclusion of all workshops, detailed workshop notes collected by trained volunteers were inductively labeled (often using key phrases repeatedly used by participants) and sorted, using grounded theory (Glasser and Strauss 2011; Walsh et al. 2015). Grounded theory - while well established in the social sciences - constitutes a methodological innovation in archetype analysis. It begins from stakeholder's own perceptions of a given matter of concern and tries to understand how they explain those matters (rather than impose a theory- or ideologically driven explanation on stakeholders' views). While not focused on establishing consensus views, grounded theory identifies (sets of) issues mentioned

\footnotetext{
${ }^{33}$ These methodological approaches differ in the degree to which they seek statistical associations between observed phenomena and to what extent they try to discern causal patterns underlying those observed phenomena. In our analysis we combine these by starting with repeatedly observed phenomena and then try to understand the underlying causal drivers, using stakeholders' own perceptions of these causal relationships.
} 
repeatedly, and then uses those repeated issues to anchor subsequent rounds of analysis that focus on understanding underlying explanations and repercussions of the noted challenges. The analyst's role is to look for patterns among the problems identified across all workshops (in this case, across regions, types of climate risks, types and sizes of local government entities etc.), as well as among the explanatory factors underlying them and for associated consequences of those constellations.

In the first read, the workshop notes were screened independently by two researchers (Moser and Ekstrom) for repetitive themes or funding challenges; subsequent reads involved identifying associated challenges, contributing factors (underlying causes and conditions), and consequences of the challenges identified. Care was taken to retain the associations between factors as they were discussed by workshop participants, rather than separating them on the basis of some pre-conceived logic. In other words, the analysis was not driven by any single theory or underlying framework (as is called for in the typical, deductive approaches to archetype analysis, see, e.g., Eisenack 2012), but rather adhered to the inductive approach of grounded theory. Moreover, initial rounds of identifying finance challenges revealed factors not captured in any single applicable theory. For example, diagnostic approaches to understanding institutional barriers to adaptation (e.g., Oberlack 2017), make "funding resources" one of several explanatory variables of adaptation outcomes, but provide little depth to the many dimensions of these funding resources that are of central interest to this study. Other approaches have a sufficiently broad empirical basis to propose directional interactions among explanatory factors and expected outcomes that we deemed inappropriately early for a first-order identification and understanding of archetypal funding challenges (e.g., Kimmich 2013). However, the observed preponderance of institutional factors caused us subsequently also to examine the workshop notes deductively for additional items typically highlighted in studies of institutional settings and governance systems (e.g., Ostrom 2007, 2009, 2014; Young 2010). Our analysis also retained information about where particular challenges were identified (i.e., the region or sector); however, this turned out to be of small if any relevance, as nearly all core challenges associated with adaptation funding where identified in nearly every region and most cut across sectors.

Iterative and recursive post-workshop processing of workshop notes by the researchers in this fashion helped repeated adaptation funding challenges to rise to the fore. They revealed characteristic associations among:

- observed funding challenges (often, the first-order complaint or problem experienced);

- core anchors or focal points ${ }^{4}$ of each challenge (an organizing principle that associated the observed challenge within a stage or logical sequence in the process of obtaining/using adaptation funding);

- a set of underlying contributory factors or attributes (stakeholders' own explanations for why these problems existed); and

- characteristic (and defining) outcomes on their ability to proceed with acquiring/using adaptation funds.

\footnotetext{
4 "Anchor" and "focal point" are used interchangeably in the text. The phrase implies a characteristic temporal dimension of when the archetype occurs in the overall process of obtaining/using funding. In this way, the full suite of archetypes is logically, sequentially organized.
} 
Differently put, each archetype is constituted of these four dimensions: an observed phenomenon occurring (or anchored) at a key stage in the funding process, caused by a characteristic set of underlying and interacting drivers, resulting in defining outcomes.

In this way, the analysis revealed a suite of 15 unique archetypes, several with notable sub-types/variants or specific expressions in different contexts. These subtypes were labeled as such when the anchor/focal point, underlying drivers and characteristic outcomes were still very much like those of the main archetype, but there were slight variations in the way they expressed themselves in different contexts (e.g., differences by region or by climate risk). This variation, however, did not warrant the establishment of an entirely new archetype. In fact, stakeholders themselves on occasion used phrases like "another way this same problem shows up is...", to illustrate this variation on a theme, rather than giving a sense of an entirely different finance challenge. 
Appendix 2. Archetypes: problems and solutions.

Below we provide detailed tables for each archetype. The tables summarize key characteristics describing the funding challenge and list interventions that may address them. These interventions were generated by workshop participants themselves and should be considered important but only partial solutions to each finance challenge.

Table A2.1: Characteristics, Underlying Causes and Potential Solutions to Address the Low Priority Archetype

\begin{tabular}{|c|c|}
\hline Characteristics and Causes & Potential Solutions \\
\hline $\begin{array}{l}\text { - The "tragedy of urgency" (or of immediacy), } \\
\text { i.e., the constant pressure from immediate } \\
\text { needs, daily demands or other pressing issues } \\
\text { - } \quad \text { Backlog of other important issues that are not } \\
\text { being addressed } \\
\text { - The lack of understanding of climate change } \\
\text { risks and lack of interest or even disbelief and } \\
\text { avoidance (among leaders and stakeholders) } \\
\text { - Lack of legitimacy of the adaptation issue } \\
\text { (sometimes vis-à-vis mitigation) } \\
\text { - Difficulty linking adaptation to core mission and } \\
\text { difficulty defining an overarching goal to work } \\
\text { towards together } \\
\text { - Lack of measures of success, progress, or } \\
\text { performance } \\
\text { Doing adaptation "behind the scenes" allows } \\
\text { some work to get done in the "margins" of } \\
\text { available resources, but invisibility reinforces its } \\
\text { seeming unimportance } \\
\text { Lack of higher-level mandate, requiring that } \\
\text { adaptation planning is being done }\end{array}$ & $\begin{array}{l}\text { - Education and trainings for local government } \\
\text { staff that help make the link between existing } \\
\text { core missions and adaptation; align goals, } \\
\text { policies, fundraising and implementation } \\
\text { - Help with framing, communication and } \\
\text { engagement, particularly of skeptical } \\
\text { audiences, with concrete examples, stories and } \\
\text { visuals of what adaptation looks like, and linked } \\
\text { to locally resonant values } \\
\text { - Building communities of practice among local } \\
\text { government staff to support peer learning and } \\
\text { exchange of strategies } \\
\text { - Local-to-local and local-to-state elected } \\
\text { exchange on funding needs } \\
\text { - Help with identifying measures of success and } \\
\text { progress to evaluate resilience measures } \\
\text { - Periodic evaluation of grant programs to show } \\
\text { what is working will generate more interest and } \\
\text { improve applications, efforts } \\
\text { - Make planning allocation based on population } \\
\text { size, without application, but mandate that } \\
\text { adaptation planning is undertaken }\end{array}$ \\
\hline
\end{tabular}

Source: The Authors

Table A2.2: Characteristics, Underlying Causes and Potential Solutions to Address the Lack of Leadership Archetype

\begin{tabular}{|l|l|}
\hline \multicolumn{1}{|c|}{ Characteristics and Causes } & \multicolumn{1}{|c|}{ Potential Solutions } \\
\hline - $\begin{array}{l}\text { A sense of weak government and lack of } \\
\text { empowerment, particularly problematic when } \\
\text { among top-level executives }\end{array}$ & $\begin{array}{l}\text { - Much greater emphasis on education of local } \\
\text { leaders and joint strategizing among them so } \\
\text { they feel more comfortable taking on adaptation }\end{array}$ \\
$\begin{array}{l}\text { - Lack of a long-term vision, or ability to generate } \\
\text { one, myopic thinking, lack of galvanizing }\end{array}$ & $\begin{array}{l}\text { - Education of the public about climate change } \\
\text { and to increase governance literacy so people } \\
\text { can put pressure on their elected leaders and }\end{array}$ \\
\hline
\end{tabular}


energy, resistance to change, and weak action

- The "politics" of taking on climate change, particularly (but not only) in conservative contexts

- Lack of higher-level mandate, providing cover for local-level officials to take up adaptation

- Need of a "perfect storm of leadership" with multiple individuals pulling together know when and where to speak out

- Local and statewide mandates to provide cover

- Neighboring community leaders serving as ambassadors to those not yet taking action

- Within government entities, fostering a risktaking organizational culture ("we have to fail a little to find success")

- Research and messaging on co-benefits and positive benefit-cost ratios

- Create narrative of mitigation and adaptation synergies and complementarity that resonates

- Pressure from rating agencies (such as Moody's) and potential liability lawsuits are likely to spur greater leadership. ${ }^{1}$

Source: The Authors

Table A2.3: Characteristics, Underlying Causes and Potential Solutions to Address the Conflict of Interest Archetype

\begin{tabular}{|c|c|}
\hline Characteristics and Causes & Potential Solutions \\
\hline 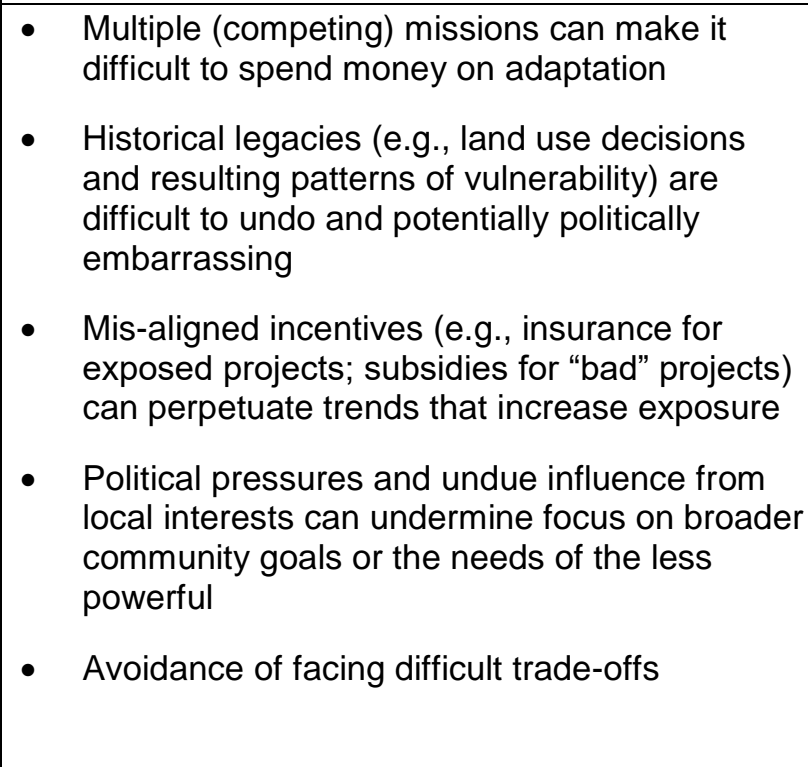 & $\begin{array}{l}\text { - } \begin{array}{l}\text { Education and training in how adaptation } \\
\text { strategies can be linked to the core mission }\end{array} \\
\text { - Shifting of "zero-sum" narratives to "shared } \\
\text { opportunity" narratives where communities } \\
\text { learn to act together and shift priorities together } \\
\text { - } \quad \text { Need insurance companies to come to the } \\
\text { table with local (and higher-level) governments } \\
\text { to foster better alignment, identify strategies } \\
\text { that redirect development into safer locations } \\
\text { - } \quad \text { Identify strategies to move away from } \\
\text { dependence on revenue from greenhouse gas } \\
\text { emitting activities } \\
\text { - Need process to rethink fundamentally how } \\
\text { existing (dis)incentives (e.g., tax structure, } \\
\text { subsidies, lack of risk disclosure) undermine } \\
\text { the financial future of local government }\end{array}$ \\
\hline
\end{tabular}

Source: The Authors

\footnotetext{
${ }^{1}$ This suggestion was added post-stakeholder workshops to reflect recent development in the financial and legal world, though at the time of the workshops it was not mentioned.
} 


\section{Table A2.4: Characteristics, Underlying Causes and Potential Solutions to Address the Disproportionate Burden Archetype}

\begin{tabular}{|c|c|}
\hline Characteristics and Causes & Potential Solutions \\
\hline $\begin{array}{l}\text { - Long histories of institutionalized racism, } \\
\text { neglect of remote and low-income } \\
\text { communities, legacies of deferred } \\
\text { infrastructure maintenance, persistent lack of } \\
\text { investment in education, diverse local } \\
\text { economies, health care, or environmental } \\
\text { protection } \\
\text { - } \quad \text { Current problems are all-demanding } \\
\text { - } \quad \text { Long-standing vulnerabilities and lack of local } \\
\text { governments' adaptive capacity } \\
\text { - Outdated models of local governance with } \\
\text { limited opportunity for meaningful stakeholder } \\
\text { engagement } \\
\text { - Limited political voice } \\
\text { - Limited cash flow or reserves to divert to } \\
\text { thinking about adaptation/the future } \\
\text { Perceived political/cultural limits to raise } \\
\text { additional fees or taxes }\end{array}$ & 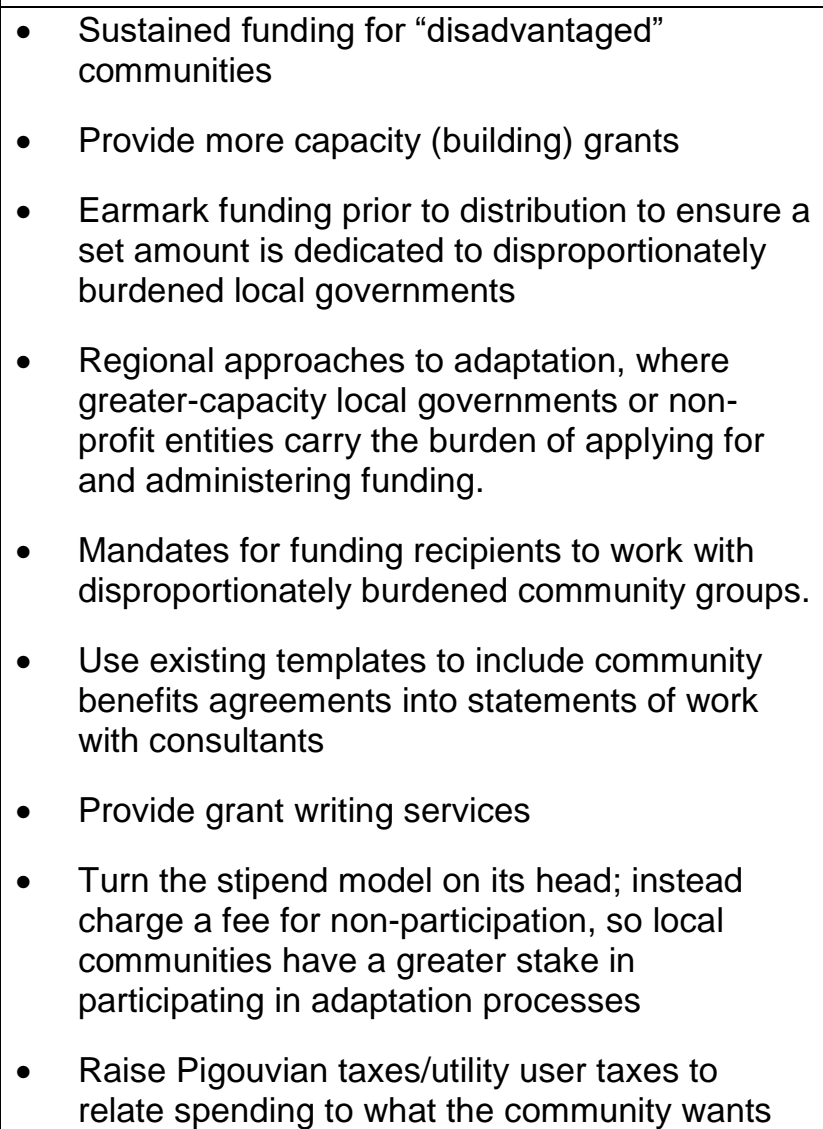 \\
\hline
\end{tabular}

Source: The Authors

Table A2.5: Characteristics, Underlying Causes and Potential Solutions to Address the Inappropriate Funding Scale Archetype

\begin{tabular}{|l|l|}
\hline \multicolumn{1}{|c|}{ Characteristics and Causes } & \multicolumn{1}{|c|}{ Potential Solutions } \\
\hline - $\begin{array}{l}\text { Scale mismatch between global change } \\
\text { problem and local capacity to address its } \\
\text { impacts }\end{array}$ & $\begin{array}{l}\text { Need for WWII mobilization to address } \\
\text { mitigation and adaptation (and thereby contain } \\
\text { the problem to something more manageable) }\end{array}$ \\
- $\begin{array}{l}\text { Responsibility for climate adaptation is } \\
\text { incommensurate with responsibility for climate } \\
\text { change problem }\end{array}$ & $\begin{array}{l}\text { Need for State and federal solutions at bigger } \\
\text { scale (e.g., funded mandates, changes in } \\
\text { statewide tax law, block grants etc.) }\end{array}$ \\
- Inefficiency of project-by-project approach to \\
$\begin{array}{l}\text { adaptation and adaptation finance } \\
\text { - } \begin{array}{l}\text { Problem of piecemeal interventions when } \\
\text { systemic solutions are needed }\end{array}\end{array}$ & $\begin{array}{l}\text { Alternatively, assume that there will be no State } \\
\text { or federal money forthcoming, to spur radical } \\
\text { rethinking and solutions }\end{array}$ \\
- $\begin{array}{l}\text { Lack of capacity of local governments to take } \\
\text { on long-term funding challenge }\end{array}$ & $\begin{array}{l}\text { Need for an empowered regional authority to } \\
\text { apply for and receive significant regional } \\
\text { adaptation funds, with clear on decision- } \\
\text { making, control and disbursement rules }\end{array}$ \\
\hline
\end{tabular}




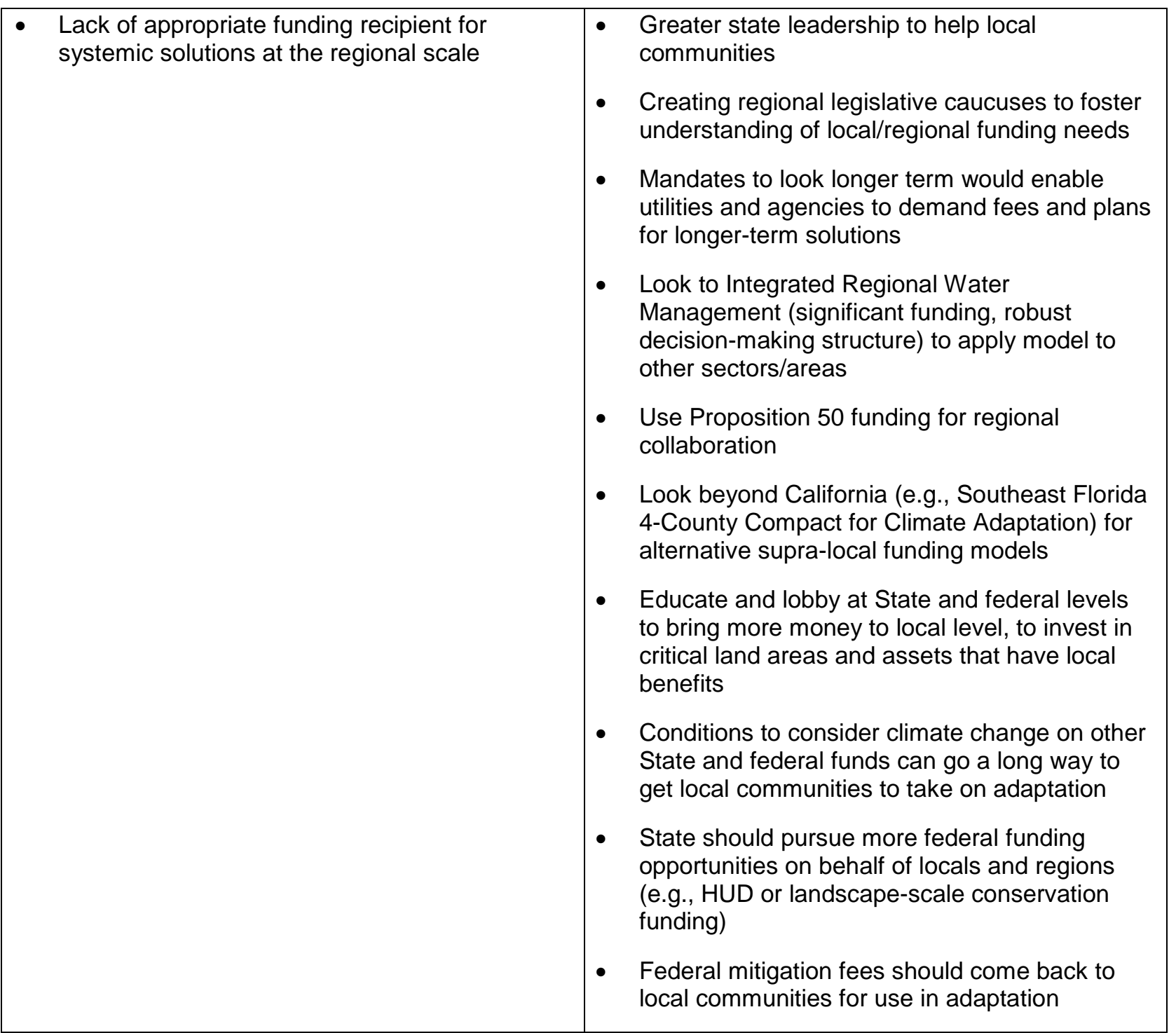

Source: The Authors

Table A2.6: Characteristics, Underlying Causes and Potential Solutions to Address the Disjointed Risk Structure Archetype

\begin{tabular}{|c|c|}
\hline Characteristics and Causes & Potential Solutions \\
\hline $\begin{array}{l}\text { - The true risk and cost is not borne by those } \\
\text { who enjoy the greatest benefit } \\
\text { - Disconnect between "the public dollar and the } \\
\text { private gain" } \\
\text { - Subsidies and incentives to live in risky places, } \\
\text { while undermining the ability to collect sufficient } \\
\text { funding for adaptation } \\
\text { - Interest politics prevent frank and early } \\
\text { disclosure of true risks }\end{array}$ & 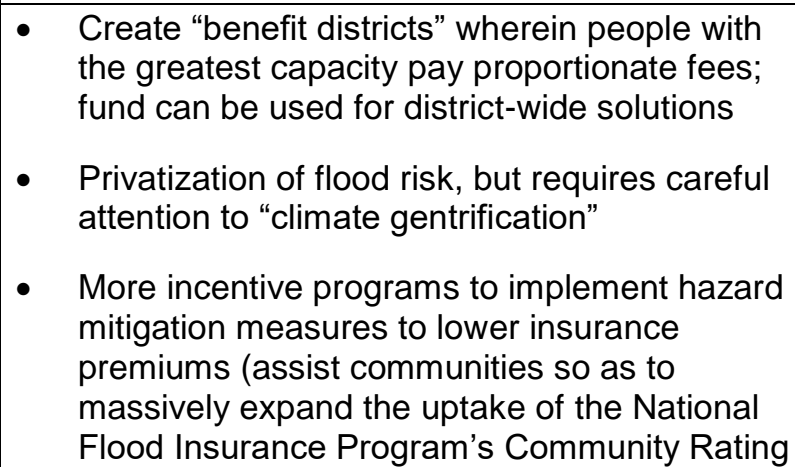 \\
\hline
\end{tabular}


- Institutionalization of disjointed risk structure

- Short-term private profit thinking prevails over longer-term community benefit thinking

- In addition to risk disconnect (which is essentially a temporal disconnect), there is also a geographic disconnect between resource or commodity producers and users (e.g., watershed stewardship and downstream use; species conservation and ecosystem services)

\section{System)}

- Establish success metrics of adaptive design in risky locations so investors and developers can see the benefit of investment and long-term planning

- $\quad$ Build pay-for-ecosystem-service alliances between urban and rural areas, upstream and downstream local governments to build resource security for some and generate the necessary means to protect those resources for others

Source: The Authors

Table A2.7: Characteristics, Underlying Causes and Potential Solutions to Address the Inability to Make Economic Case Archetype

\begin{tabular}{|l|}
\hline \multicolumn{1}{|c|}{ Characteristics and Causes } \\
\hline - $\quad \begin{array}{l}\text { Inability to illustrate the need for and benefits of } \\
\text { adaptation and to justify the expense for } \\
\text { climate adaptation vis-à-vis other budget items }\end{array}$
\end{tabular}

- $\quad$ Lack of economic training and expertise among local government staff

- $\quad$ Lack of tools to do the requisite economic assessments

- Lack of knowledge of what different adaptation aspects might cost

- The complexity of adaptation projects (and lack of economic assessment tools to match that complexity)

- Lack of metrics of success or performance to help show the benefits of investment and to prioritize adaptation strategies

- Bias toward "dollars and cents" as the common denominator in assessments, hindering proper appreciation of non-monetized values

- Rules of doing benefit-cost analyses can bias against strategies where benefits only accrue over the long term

- Lack of public and political support for longterm investments

- Political challenges of dealing with difficult trade-offs

\section{Potential Solutions}

- Advancing research on adaptation costs and benefits

- Advances in establishing common sets of metrics of success and performance; development of some metrics at least should be done with financial experts to ensure they hear what they need to be willing to invest

- Development of tools, alongside trainings to use those tools in combination with legal requirements to use them would help staff and consultants perform valuations of monetized and non-monetized risks and benefits

- Staff trainings in economic assessment tools (particularly in combination with requirements or incentives to use them)

- Moving adaptation funding from grant-based, project-based funding to established budget line-item to minimize project-by-project justification need

- Foundation investment in tool development and demonstration projects

- Support project pre-development phase through dedicated adaptation services to help make the link between public sector adaptation and private-sector investors 
Table A2.8: Characteristics, Underlying Causes and Potential Solutions to Address the Chronic Underfunding Archetype

\begin{tabular}{|c|}
\hline Characteristics and Causes \\
\hline $\begin{array}{l}\text { - General US culture of limited government } \\
\text { Widespread tax aversion across American } \\
\text { society } \\
\text { - Tax-restricted state since } 1978 \text { when } \\
\text { Californians voted in favor of Proposition } 13 \\
\text { ( } 2 / 3 \text { majority required to change taxation); } \\
\text { taxes come with certain use restrictions }\end{array}$ \\
\hline
\end{tabular}

- $\quad$ Special fees $(50+1$ majority required) are easier to raise but are more restricted in use

- Chronic insufficiency of local funding and chronic underinvestment in infrastructure

- Internal competition for limited general funds

- Growing dependence on external grant funding and significant staff time required to write grants

- Larger, high-capacity cities and counties tend to have better success rates than smaller, lower-capacity local governments, a selfreinforcing situation

- Popular sense that Californians are over-taxed, yet expectation that government should pay for adaptation and functional community services

\section{Potential Solutions}

- Rethink fundamentally and reconsider approaches to local taxation in California

- Rethink adaptation fundamentally as widespread community redevelopment into resilient, safer communities

- Use existing funds for climate-safe redevelopment creatively and tap/re-purpose existing non-adaptation funding streams (e.g., Clean Air Act, Clean Water Act, agricultural funding sources)

- Mainstream climate change adaptation into existing funding streams

- Explore more "carrot and stick" approaches to get adaptation done

- Access non-traditional funding sources, e.g. international competitions to pilot and showcase potential adaptation solutions

- Provide training to become better at accessing state and federal-level funding sources

- Integrate training on (institutionalized) racism and how to embed equity into funding applications and adaptation approaches to make systemic changes

- Establish relationships with private sector to design innovative financing vehicles

- Educate local government staff on how to effectively work with private sector and/or support "boundary organization" navigating between local public sector and international and national private/investment sector

- Move money out of unsustainable sectors (subsidies for oil) and move into resilience

- Partner with non-profits whereby they apply for funds and do key work on their own and local government's behalf but don't lose sight of integrating climate change within all aspects of local government 


\section{Table A2.9: Characteristics, Underlying Causes and Potential Solutions to Address the Siloed Government Archetype}

\begin{tabular}{|c|c|}
\hline Characteristics and Causes & Potential Solutions \\
\hline 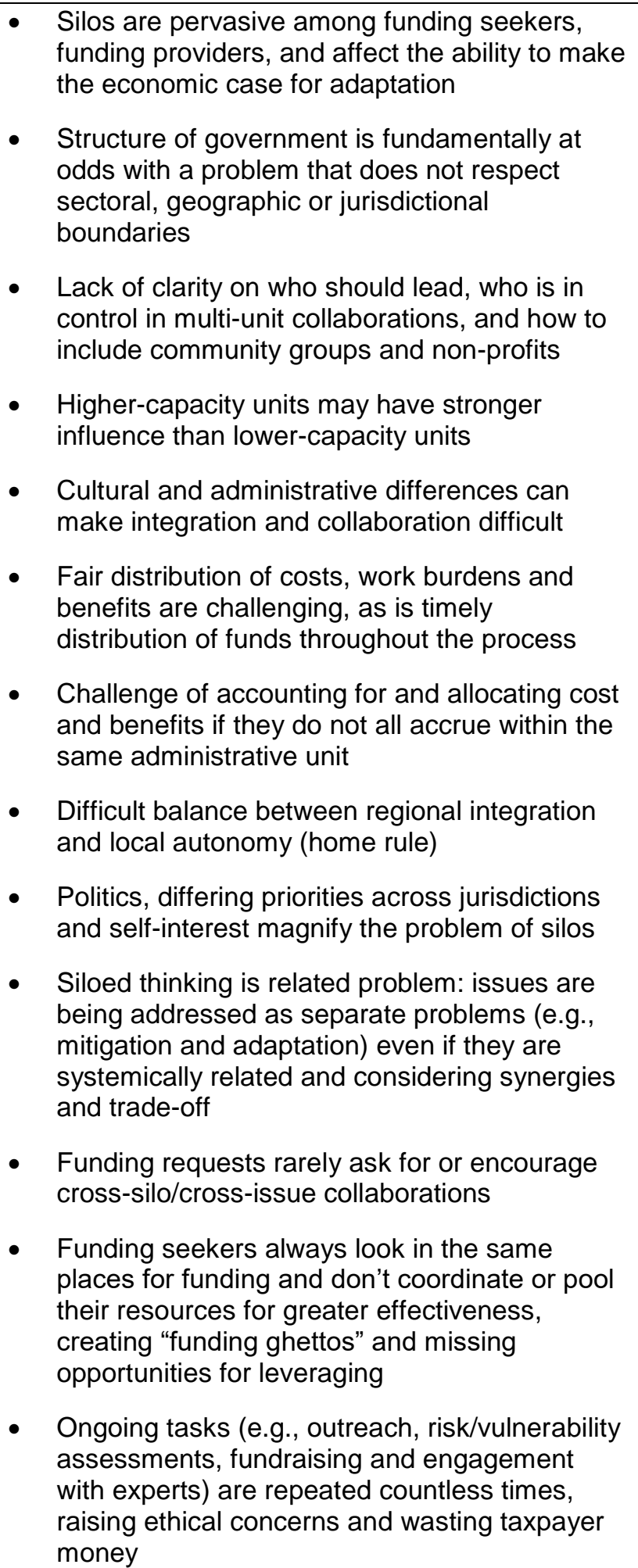 & 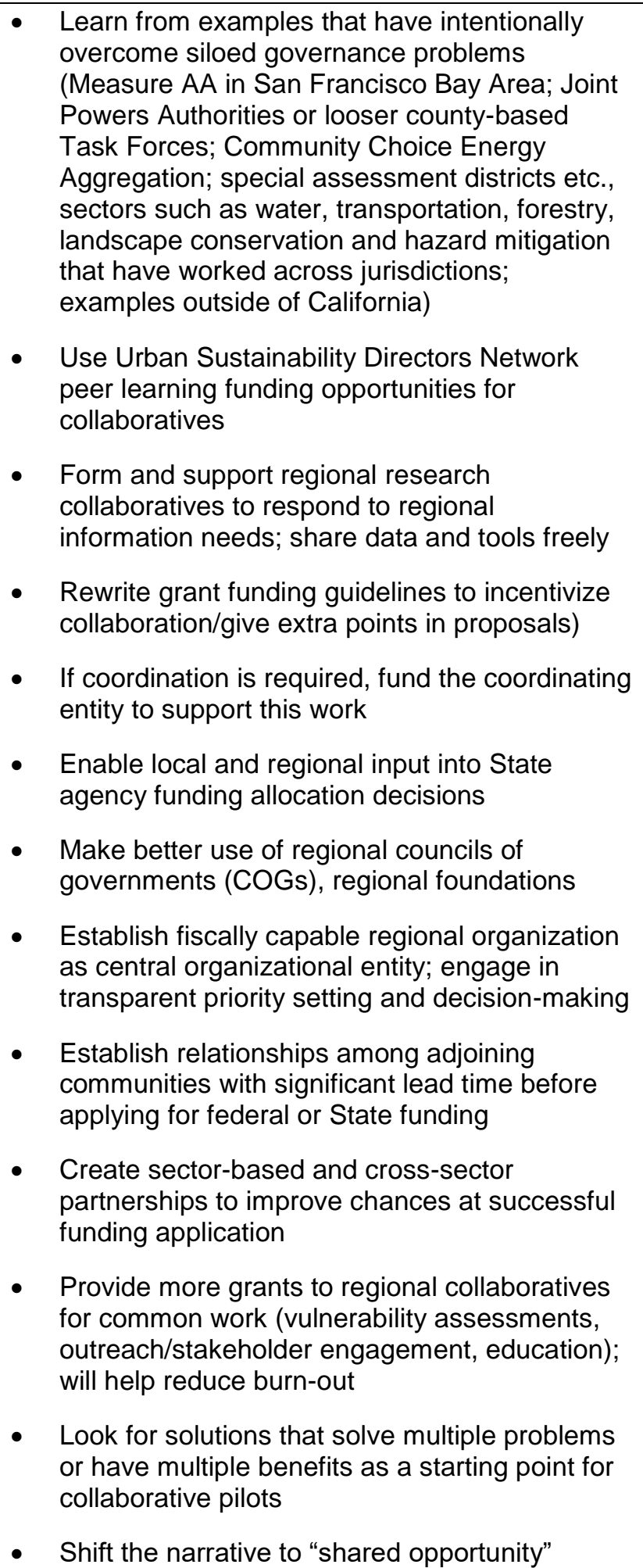 \\
\hline
\end{tabular}


- The bigger the collaboration, the greater the challenges of managing complex projects

- Varying capacities, requirements and access to officials (e.g., in work with tribes) or very different organizational cultures, mindsets and functional time scales can inhibit efforts in breaking down silos
- Need big-picture thinkers as leaders of regional, integrated efforts

- Streamline regulations and permitting process as well to reduce cost and time of permitting adaptation projects

- Integrate adaptation in virtually every job description to make everyone feel responsible for it getting done; educate and train staff (e.g., climate change, funding, systems thinking, social equity

Source: The Authors

\section{Table A2.10: Characteristics, Underlying Causes and Potential Solutions to Address} the Lack of Capacity (I) Archetype

\begin{tabular}{|l|}
\hline \multicolumn{2}{|c|}{ Characteristics and Causes } \\
\hline - \\
Many local governments are significantly staff \\
constrained, either due to chronic lack of funds, \\
currently "being in the red," or not having rebuilt \\
full staff capacity after the recession \\
- Staff must wear many hats; few have the luxury \\
to have a dedicated "adaptation person"
\end{tabular}

- Staff turn-over/retirements of long-term staff is always problematic, but particularly for shortterm projects and grants (lack of institutional memory)

- Limited staff capacity affects time for looking for funding opportunities, time for writing grant applications, and ability to write competitive applications

- $\quad$ Low confidence in ability to succeed with grant writing can undermine the willingness to apply

- Burden to apply for small grants $(\$ 20 K)$ is nearly as great as for bigger grants $(\$ 100 \mathrm{~K})$ and grant writing requirements can be onerous; work burden may outweigh financial benefit

- Grants for capacity building and training or to build up the "development" arm of local government are extremely limited

- Expertise in adaptation may be low (even if there is grant-writing capacity)

- "Best practice list for adaptation" and greater knowledge in how to quantify cost and benefits of adaptation would make application easier

- Difficulty seeing opportunities for leveraging

\section{Potential Solutions}

- Review and reduce onerous grant-writing requirements in State and federal funding (esp. water boards, USACE, Federal Highway Administration); consider stipulating that funds be used in part for internal capacity building

- Size-adjust grant-writing requirements (simplify for smaller grants)

- Scale up intern and fellowship programs to assist particularly lower-capacity communities

- Mandate regular updates to plans (that include adaptation) with assured funding if the updated plan is approved

- Provide more block grants as they allow local governments to hire staff for multiple years

- Provide more technical assistance and Statesponsored training programs on adaptation, systems thinking, grant writing best practices

- Provide and use grant writing services (e.g., external specialized organizations or Countybased grant-writing assistance to smaller communities)

- Use ARCCA collaboratives or other consortia to build better relationships with scientists to make up for lack of technical expertise

- Develop public-private-civic partnerships to help disproportionately burdened and lowercapacity communities overcome initial hurdles and begin to have better access to funding

- Create pooled funds (e.g. at the regional level) and streamline application process; specifically 
- Lack of technical assistance from State and other sources for grant-finding and -writing

- Use of outside consultants can be efficient but drains available funds and prevents the building up of internal capacity (vicious cycle of dependence on external expertise) task regional entities to administer pool or create capable, sufficiently staffed oversight or financial sponsor organizations willing to take on liability and responsibility to do so

- General Assistance Programs (similar to EPA's GAP program for tribes ${ }^{2}$ ) should be created for other types of local government

- Use the "100 Resilient Cities" as a model and build statewide program

- Provide examples of where, when and how more complicated funding mechanisms or public-private funding models were successfully used to support replication/adaptation

Table A2.11: Characteristics, Underlying Causes and Potential Solutions to Address the Discontinuous Funding Archetype

\begin{tabular}{|c|c|}
\hline Characteristics and Causes & Potential Solutions \\
\hline $\begin{array}{l}\text { - } \quad \text { General difficulty of getting longer-term funding } \\
\text { - } \quad \text { Disasters can free up a lot of money, but is } \\
\text { available quickly, unpredictably and is short- } \\
\text { term } \\
\text { - } \quad \text { Pre-disaster hazard mitigation grants are too } \\
\text { small to meet the needs } \\
\text { - } \quad \text { Grants are typically for specific projects and } \\
\text { often do not cover all aspects of adaptation- } \\
\text { related work, leaving many aspects (e.g., } \\
\text { outreach, collaboration) unfunded } \\
\text { - } \quad \text { Lack of experience with investment funds and } \\
\text { financing mechanisms (especially with private } \\
\text { sector involvement) } \\
\text { Mainstreaming adaptation expenses into } \\
\text { general funds or creating budget line items is } \\
\text { possible, but difficult for chronically under- } \\
\text { resourced communities }\end{array}$ & $\begin{array}{l}\text { - Provide block grants for longer-term continuous } \\
\text { funding } \\
\text { - Establish a "Climate Resilience Authority" to } \\
\text { aggregate risk and pool risk insurance } \\
\text { premiums into a regional fund), set asset } \\
\text { retirement obligations over time, invest in } \\
\text { regionally significant risk reduction measures } \\
\text { (e.g., buy-outs) from funding pool to buy down } \\
\text { risk and to administer finances } \\
\text { - State should facilitate building relationship with } \\
\text { private investors to design innovative funding } \\
\text { vehicles for long-term stable funding } \\
\text { - Use more "carrot and stick" approaches that } \\
\text { link risk reduction measures with funding } \\
\text { - Create a long-term vision and intermediate } \\
\text { milestones to measure progress against, so } \\
\text { that people see progress over time. } \\
\text { - Establish post-disaster rebuilding } \\
\text { requirements/criteria to ensure adaptation is } \\
\text { built into the recovery } \\
\text { - Have post-disaster adaptation plans ready to } \\
\text { go, so that opportunities of post-disaster } \\
\text { funding don't pass by untapped }\end{array}$ \\
\hline
\end{tabular}

Source: The Authors

\footnotetext{
${ }^{2}$ See: https://www.epa.gov/tribal/indian-environmental-general-assistance-program-gap.
} 
Table A2.12: Characteristics, Underlying Causes and Potential Solutions to Address the Aversion to Innovation Archetype

\begin{tabular}{|c|c|}
\hline Characteristics and Causes & Potential Solutions \\
\hline 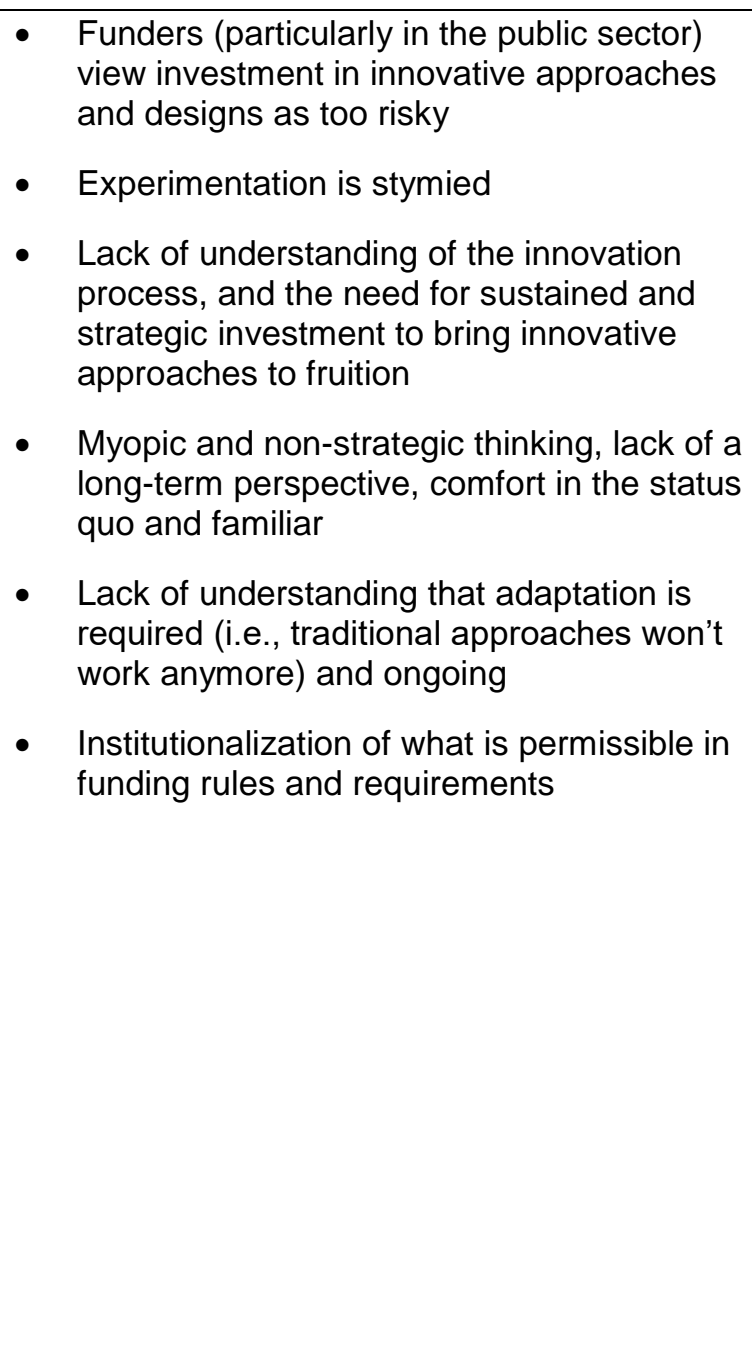 & $\begin{array}{l}\text { - Work through the rule-making process at } \\
\text { relevant agencies to change funding } \\
\text { requirements } \\
\text { - Invest in demonstration projects to show what } \\
\text { works, what is cost-effective and other lawful } \\
\text { co-benefits of innovative ideas } \\
\text { - Establish pilot programs, especially to spur } \\
\text { innovation and test effectiveness, without } \\
\text { immediately requiring wholesale program } \\
\text { changes } \\
\text { - Provide strong state-level leadership to direct } \\
\text { agencies appropriately } \\
\text { Tap into new narratives and values to make the } \\
\text { new attractive (rather than a threat to the } \\
\text { familiar), e.g., risk aversion to bad things as } \\
\text { opposed to risk aversion to new things } \\
\text { Invest much more in outreach to overcome } \\
\text { resistance to science, reality of change } \\
\text { Seek out foundations that support innovation to } \\
\text { pilot test new ideas } \\
\text { Task certain organizations with identifying } \\
\text { innovative, best practice approaches for local } \\
\text { governments } \\
\text { State should use and invest in bottom-up, } \\
\text { participatory processes (crowd-sourcing, } \\
\text { competitions) to generate novel ideas; } \\
\text { permitting agencies would need to be at the } \\
\text { table from the start }\end{array}$ \\
\hline
\end{tabular}

Source: The Authors

Table A2.13: Characteristics, Underlying Causes and Potential Solutions to Address the Funding Biases Archetype

\begin{tabular}{|l|l|}
\hline \multicolumn{1}{|c|}{ Characteristics and Causes } & \multicolumn{1}{|c|}{ Potential Solutions } \\
\hline $\begin{array}{l}\text { Perception (and often reality) that there is no or } \\
\text { only insufficient funding to meet adaptation- } \\
\text { related needs }\end{array}$ & $\begin{array}{l}\text { Apply a life-cycle funding approach to } \\
\text { adaptation, with the ability to go back to the } \\
\text { same funder for later needs }\end{array}$ \\
- $\begin{array}{l}\text { One view that there is more funding for } \\
\text { implementation than for earlier and later stages } \\
\text { of adaptation }\end{array}$ & $\begin{array}{l}\text { Change funding requirements for shovel-ready } \\
\text { projects to mandate inclusion of "soft" aspects } \\
\text { of adaptation (outreach, engagement, planning, } \\
\text { monitoring and evaluation over time) }\end{array}$ \\
A second (dominant) view that there is more & Look to other models for "whole-project \\
\hline
\end{tabular}


funding for planning than for implementation

- Bias toward discrete projects

- Bias against broader, programmatic efforts

- Bias toward structural adaptation measures (coastal, water, infrastructure), while neglecting human health impacts

- Bias against adaptation options that are very expensive and politically contested

- Lack of political and public support for expensive and contested adaptation options

- Lack of knowledge of what funding sources are available

- $\quad$ Lack of clear measures of success and progress for programmatic efforts funding" (e.g., California Building Healthy Communities 10-year funding model)

- Conduct more outreach and education to help communities understand adaptation needs, outlook over the long-term

- Conduct cost-effectiveness studies to illustrate effectiveness

- Invest in efforts to develop measures of progress and success

Source: The Authors

Table A2.14: Characteristics, Underlying Causes and Potential Solutions to Address the Happenstance Archetype

\begin{tabular}{|c|}
\hline Characteristics and Causes \\
\hline $\begin{array}{l}\text { - Siloed nature of funding sources } \\
\text { - Many foundations fund relevant "bits and } \\
\text { pieces" but only a relatively small number focu } \\
\text { on adaptation }\end{array}$ \\
\hline
\end{tabular}

- No centralized place to find funding opportunities

- Happenstance to find or learn about funding opportunities

- Capacity constraints to look for and take advantage of grant opportunities
Potential Solutions

- Easily navigable clearinghouse of funding opportunities, constantly kept up to date; but fear that it will increase competition for limited funds if more know about them

- Host of clearinghouse should have staff capacity to maintain, push out, and do some hand-holding of funding seekers; alternatively work closely with regional collaboratives or regional adaptation assistance centers to support local governments

- Need to build up the "development" capacity of local governments, a funded staff assigned to search for grants, assign them to departments and assist technical staff in writing successful applications

- Introduce and pass State legislation for PACElike program for adaptation-related needs (at the level of property owners)

- Host California-based foundation summit to help foundations see why adaptation needs to become part of their portfolios

- Create a statewide dedicated Climate Adaptation Fund

- State and adaptation service providers should provide more technical assistance to local 


\begin{tabular}{|l|l|}
\hline & $\begin{array}{l}\text { governments } \\
\text { Use of B Corporations, venture trust funds etc. } \\
\text { to launch adaptation initiatives; then get bigger } \\
\text { investments from private sector }\end{array}$ \\
\hline
\end{tabular}

Source: The Authors

Table A2.15: Characteristics, Underlying Causes and Potential Solutions to Address the Eligibility Archetype

\begin{tabular}{|c|}
\hline Characteristics and Causes \\
\hline $\begin{array}{l}\text { - Lack of clarity on eligibility criteria or } \\
\text { application not meeting them } \\
\text { - Difficulty understanding grants and application } \\
\text { process }\end{array}$ \\
\hline
\end{tabular}

- Certain types of funding are restrictive and can't be used for adaptation activities (e.g., building back better or using adaptive designs can be prevented by requirements to build back the same)

- Existing mandates, rules and regulations may be so narrowly defined and restrictive that adaptive measures can't be integrated and staff can't apply for available funds

- Need to patch funding together from multiple sources to compensate for restrictions

- Patch-work approach is time consuming and difficult to impossible for staff-constrained communities; undermines implementation of a broader vision

- Matching fund requirements can undermine lower-capacity communities' ability to take advantage even where funds are available

- If funding applications require a lot of prior planning or development work, timelines and opportunities are missed

- Legacies and bad past experiences with certain funders (e.g., regulatory agencies) can bias against repeated application or engagement with funder

- Legacies (e.g., being in non-attainment of certain regulations; lack of structural soundness of buildings) can undermine eligibility for grant funding or ability to use certain adaptation strategies
- $\quad$ Add adaptation criteria to existing funding streams and related legal frameworks

- Establish dedicated "transition funds" (additional to other funding) so people have the necessary means to move out of old ways of doing things to new ways

- Establish a pool of matching funds that small communities can tap into for grants that require them

- Update codes, standards and guidelines to incorporate changing conditions and enable mainstreaming adaptation

- Strengthen code implementation to ensure adaptation is incorporated

- Revisit definition of "disadvantaged", "diversity" and "vulnerability" in State code, CAL Environscreen and other grant stipulations, which can be too limiting at the local level

- Review CEQA and ensure that it accounts for climate change impacts and makes explicit space for adaptation

- Review conditions on mitigation grants and make room for adaptation co-benefits

- Add adaptation criteria to GGRF

- For communities that prepare separate general and hazard mitigation plans, integrate at the next update to create cost efficiencies and better integration across the community

Source: The Authors 
Table A2.16: Characteristics, Underlying Causes and Potential Solutions to Address the Lack of Capacity (II) Archetype

\begin{tabular}{|l|l|}
\hline \multicolumn{1}{|c|}{ Characteristics and Causes } & \multicolumn{1}{|c|}{ Potential Solutions } \\
\hline - $\begin{array}{l}\text { Lack of staff capacity to administer complex or } \\
\text { multiple grants; serves as disincentive to apply } \\
\text { for funding }\end{array}$ & $\bullet \begin{array}{l}\text { Establish and support capable lead } \\
\text { organizations to assist local communities in } \\
\text { grant administration or do it for them entirely }\end{array}$ \\
- $\begin{array}{l}\text { Lack of skill in administering complicated } \\
\text { funding models }\end{array}$ & - $\begin{array}{l}\text { Trainings in grant administration } \\
\text { - } \begin{array}{l}\text { Lack of capacity to implement a project (for a } \\
\text { variety of reasons) creates a disincentive to } \\
\text { apply for funding } \\
\text { Onerous reporting requirements }\end{array}\end{array}$ \\
\hline
\end{tabular}

Source: The Authors 